Article

\title{
Phyllanthus Niruri Standardized Extract Alleviates the Progression of Non-Alcoholic Fatty Liver Disease and Decreases Atherosclerotic Risk in Sprague-Dawley Rats
}

\author{
Raghdaa Hamdan Al Zarzour ${ }^{1, *}$, Mariam Ahmad ${ }^{1, *}$, Mohd. Zaini Asmawi ${ }^{1}$, Gurjeet Kaur ${ }^{2}$, \\ Mohammed Ali Ahmed Saeed ${ }^{3}$ (D), Majed Ahmed Al-Mansoub ${ }^{1}$, \\ Sultan Ayesh Mohammed Saghir ${ }^{1}$, Nasiba Salisu Usman ${ }^{1}$, Dhamraa W. Al-Dulaimi ${ }^{1}$ \\ and Mun Fei Yam ${ }^{1}$ \\ 1 Discipline of Pharmacology, School of Pharmaceutical Sciences, Universiti Sains Malaysia, Penang 11800, \\ Malaysia; amzaini@usm.my (M.Z.A.); madjed_25@yahoo.fr (M.A.A.-M.); \\ sultan_a1976@yahoo.com (S.A.M.S.); nasibausman@gmail.com (N.S.U.); dhamora@yahoo.com (D.W.A.-D.); \\ yammunfei@yahoo.com (M.F.Y.) \\ 2 Institute for Research in Molecular Medicine (INFORMM), Universiti Sains Malaysia, Penang 11800, \\ Malaysia; gurjeet@usm.my \\ 3 Discipline of Pharmaceutical Chemistry, School of Pharmaceutical Sciences, Universiti Sains Malaysia, \\ Penang 11800, Malaysia; mohali141@yahoo.com \\ * Correspondence: raghdaa.alzarzour@yahoo.com (R.H.A.Z.); mariam@usm.my (M.A.)
}

Received: 16 May 2017; Accepted: 12 July 2017; Published: 18 July 2017

\begin{abstract}
Non-alcoholic fatty liver disease (NAFLD) is one of the major global health issues, strongly correlated with insulin resistance, obesity and oxidative stress. The current study aimed to evaluate anti-NAFLD effects of three different extracts of Phyllanthus niruri (P. niruri). NAFLD was induced in male Sprague-Dawley rats using a special high-fat diet (HFD). A 50\% methanolic extract (50\% ME) exhibited the highest inhibitory effect against NAFLD progression. It significantly reduced hepatomegaly $(16 \%)$ and visceral fat weight $(22 \%)$, decreased NAFLD score, prevented fibrosis, and reduced serum total cholesterol (TC) (48\%), low-density lipoprotein (LDL) (65\%), free fatty acids (FFAs) (25\%), alanine aminotransferase (ALT) (45\%), alkaline phosphatase (ALP) (38\%), insulin concentration (67\%), homeostatic model assessment of insulin resistance (HOMA-IR) (73\%), serum atherogenic ratios TC/high-density lipoprotein (HDL) (29\%), LDL/HDL (66\%) and (TC-HDL)/HDL $(64 \%)$, hepatic content of cholesterol (43\%), triglyceride (29\%) and malondialdehyde (MDA) $(40 \%)$ compared to a non-treated HFD group. In vitro, 50\% ME of P. niruri inhibited $\alpha$-glucosidase, pancreatic lipase enzymes and cholesterol micellization. It also had higher total phenolic and total flavonoid contents compared to other extracts. Ellagic acid and phyllanthin were identified as major compounds. These results suggest that $P$. niruri could be further developed as a novel natural hepatoprotective agent against NAFLD and atherosclerosis.
\end{abstract}

Keywords: Phyllanthus niruri; non-alcoholic fatty liver disease (NAFLD); insulin resistance; atherosclerosis; $\alpha$-glucosidase; pancreatic lipase; cholesterol micellization; ellagic acid; phyllanthin

\section{Introduction}

Non-alcoholic fatty liver disease (NAFLD) is the hepatic manifestation of metabolic syndrome, which is highly associated with several metabolic disorders such as type 2 diabetes mellitus (T2DM), insulin resistance (IR) and hyperlipidemia [1,2]. In the absence of excessive alcohol ingestion, obesity is one of the major etiological factors of NAFLD, which is characterized by an accumulation of 
triglycerides inside the liver cells to a percentage exceeding $5 \%$ of liver weight [3], with the same histopathological manifestations of an alcoholic liver injury [4]. During the last two decades, its prevalence has reached worrying proportions as it has come to affect $25.2 \%$ of the people worldwide [5], including $20-30 \%$ of adults and $3-10 \%$ of children in Western countries [6]. NAFLD was reported as the main factor in many of the morbidities related to liver diseases [7]. It causes various types of liver injuries, including simple hepatic fat accumulation, which may occur alone or associated with steatohepatitis, known as non-alcoholic steatohepatitis (NASH), with or without fibrosis [8,9]. It was suggested by several studies that NAFLD is the key player in increasing the incidence of hepatocellular carcinoma [10]. The pathogenesis of NAFLD is multifactorial, but it is mainly attributed to insulin resistance and imbalance in lipids (uptake, hepatic synthesis and degradation) [9]. Recently, gut dysbiosis has also been linked with NAFLD [11].

Insulin resistance and oxidative stress are essential risk factors for NAFLD [12,13]. Oxidative stress promotes the production of reactive oxygen species (ROS) that stimulate an inflammatory process in hepatic tissues [14]. On the other hand, insulin resistance inhibits the antilipolytic activity of insulin in the adipose tissue and increases free fatty acids (FFAs) in the serum and liver, leading to mitochondrial dysfunction as well as cardiac fat accumulation [15].

Over the last decade, several noteworthy research initiatives have aimed at finding possible therapies to ameliorate the hepatic damage that accompanies NAFLD. The majority of pharmacological strategies include using antioxidant agents and insulin sensitizers, and also reducing the effect of dietary carbohydrate and fats by the inhibition of cholesterol micellization, pancreatic lipase and $\alpha$-glucosidase [16-18].

Recently, a considerable number of studies has investigated natural phytochemicals as anti-NAFLD agents [19-22]. P. niruri, a herb found in South East Asia, has been traditionally used to treat many pathological conditions like dyspepsia, bronchitis, influenza, asthma, dysentery, tumours, diabetes, vaginitis and tuberculosis [23]. It was also used for its potent activity in the treatment of kidney stones and gallstones [24] and various liver disorders, particularly hepatitis and jaundice. Recent data showed that $P$. niruri had hepatoprotective properties against induced hepatitis in rats [25], and it has a therapeutic effect on T2DM, which is associated with hypercholesterolemia [26].

P. niruri is rich in flavonoids and phenolic compounds that are responsible for its potent antioxidant properties [27], which could play important roles in hepatoprotective activity [28,29]. However, to the best of our knowledge, no reports have been published regarding the therapeutic effects of $P$. niruri in the treatment of NAFLD. Thus, in this study we attempt to evaluate the potential role of P. niruri in suppressing and/or ameliorating the development of NAFLD induced by the oral administration of a high-fat diet (HFD) in rats as a model that reflects human NAFLD, using metformin as the positive control drug.

\section{Materials and Methods}

\subsection{High-Fat Diet Preparation}

A normal diet was purchased from Gold Coin Feed mills Sdn. Bhd., Penang, Malaysia (product code $702 \mathrm{P})$, which contains crude protein $(21-23 \%)$, crude fibre $(5 \%)$, crude fat $(3 \%)$, moisture $(13 \%)$, ash $(8 \%)$, calcium $(0.8 \%)$ and phosphorus $(0.6-1.0 \%)$. The high-fat diet was prepared by mixing the normal diet with $10 \%$ margarine $(\mathrm{wt} / \mathrm{wt}), 10 \%$ ghee fat $(\mathrm{wt} / \mathrm{wt}), 1 \%$ cholesterol and $0.5 \%$ cholic acid.

\subsection{Extract Preparation}

A specimen of P. niruri including whole plant was identified by Professor Mashhor Mansor from the Botany Department, School of Biological Sciences, Universiti Sains Malaysia (USM). A voucher herbarium specimen has been deposited at the Herbarium Unit (Voucher No. 11474), School of Biological Sciences, USM. A powder of dry whole plant of P. niruri was extracted by maceration using water (WE), 50\% methanol in water (50\% ME) and methanol (ME) respectively. 


\subsection{In Vivo Model}

The NAFLD animal model was developed and studied using 36 male Sprague-Dawley (SD) rats (10 weeks of age), obtained from the Animal Research and Service Centre, USM. All experimental procedures were carried out after getting the approval from Animal Ethics Committee, Universiti Sains Malaysia (protocol No.: 2013/(90) (546)).

Animals were acclimatized for one-week and randomly assigned to six groups $(n=6)$. Group 1 was fed a normal diet for eight weeks and served as the normal control group (NC), while the five remaining groups (2-6) were fed a high-fat diet (HFD) for eight weeks. Oral gavage treatment started in week 4 . Group 1 was treated with distilled water $(10 \mathrm{~mL} / \mathrm{kg}$ body weight). Group 2 was the HFD group, which served as a negative control and received distilled water $(10 \mathrm{~mL} / \mathrm{kg}$ body weight); group 3 served as a positive control and received metformin (HFD + Met $500 \mathrm{mg} / \mathrm{kg}$ body weight) at $10 \mathrm{~mL} / \mathrm{kg}$ body weight; groups $4-6$ received $1000 \mathrm{mg} / \mathrm{kg}$ of $P$. niruri $\mathrm{WE}, 50 \% \mathrm{ME}$, and ME, respectively, at $10 \mathrm{~mL} / \mathrm{kg}$ body weight

The same protocol was repeated for evaluating the dose-response relationship, using five groups. Group 1 was fed a normal diet and served as a normal control group (NC), while the four remaining groups were fed a high-fat diet (HFD) for eight weeks. Oral gavage treatment started in week 4 . Group 1 was treated with distilled water $(10 \mathrm{~mL} / \mathrm{kg}$ body weight). Group 2 served as a negative control and received distilled water $(10 \mathrm{~mL} / \mathrm{kg}$ body weight); groups 3, 4, and 5 received $1000 \mathrm{mg} / \mathrm{kg}, 500 \mathrm{mg} / \mathrm{kg}$, and $250 \mathrm{mg} / \mathrm{kg}$, respectively, of the most active extract of $P$. niruri to evaluate the relative potency of the three different doses $(1000 \mathrm{mg} / \mathrm{kg}, 500 \mathrm{mg} / \mathrm{kg}$, and $250 \mathrm{mg} / \mathrm{kg})$ at $10 \mathrm{~mL} / \mathrm{kg}$ body weight.

\subsection{Determination of Blood and Serum Biochemical Parameters}

After eight weeks of HFD feeding, all the rats were fasted overnight and the body weight of each rat was determined. They were anesthetized with sodium pentobarbital $(60 \mathrm{mg} / \mathrm{kg}$ intraperitoneal (i.p.)). Five millilitres of the blood were taken via cardiac puncture from each rat. Blood glucose level was determined using an automated blood glucose meter (Accu-chek Performa ${ }^{\circledR}$, Roche Diagnostics, Mannheim, Germany). Peri-renal fats were isolated and weighed for the assessment of visceral adipose tissues. The serum was used to measure aspartate transaminase (AST), alanine transaminase (ALT), alkaline phosphatase (ALP), total bilirubin, creatinine, uric acid, urea, low-density lipoprotein (LDL), high-density lipoprotein (HDL), total cholesterol (TC), and triglycerides (TG) levels using the Olympus AU640 ${ }^{\mathrm{TM}}$ multifunctional biochemistry analyser (laboratories of Gribbles, Penang, Malaysia).

\subsection{Determination of Insulin and Free Fatty Acids Concentrations}

Insulin levels were determined using the commercial rat insulin ELISA kit (Elabscience Biotechnology Co., Ltd., Beijing, China). Serum free fatty acids (FFAs) values were measured using a fluorometric assay kit (Cayman Chemical, Ann Arbor, MI, USA) catalogue No. 700310.

\subsection{Assessment of Atherosclerosis Risk Indexes}

Recent data showed that NAFLD is one of the independent predictors of atherosclerosis [16]. Therefore, in order to identify high-risk cases of atherosclerosis and their effective therapeutic management, the predictor ratios that complement the lipid profile ratios such as atherogenic Castelli's Risk Index I, Castelli's Risk Index II, in addition to atherogenic coefficient (AC) were determined [30].

Atherogenic ratios were calculated based on the following formulas:

$$
\begin{gathered}
\text { Castelli's Risk Index-1 (CRI-I) }=\text { TC } / H D L ; \\
\text { Castelli's Risk Index-2 (CRI-II) }=\text { LDL } / H D L ; \\
\text { Atherogenic Coefficient }(\mathrm{AC})=(\mathrm{TC}-\mathrm{HDL}) / \mathrm{HDL} .
\end{gathered}
$$




\subsection{Assessment of Lipid Peroxidation, TG and TC Contents in Liver Tissues}

Total protein content of liver tissues was determined using a Bradford assay kit (Sigma-Aldrich, San Jose, CA, USA). The MDA content was measured in the hepatic tissue homogenate by a thiobarbituric acid reaction [31]. Hepatic lipid was extracted according to Folch et al. [32]. The content of TG was determined using triglycerides colorimetric assay kit (Cayman Chemical, Ann Arbor, MI, USA), while TC content was determined using a commercial kit according to the manufacturer's protocol (Thermo Fisher Scientific, Waltham, MA, USA).

\subsection{Histopathological Examinations}

For histological analysis, the liver specimen was taken from the largest hepatic lobe and fixed with formaldehyde $10 \%(v / v)$. Histopathological examinations were performed by an experienced pathologist using a blinded approach. The liver sections were stained with hematoxylin and eosin (H\&E). The histological features were examined and grouped into four broad categories: steatosis, lobular inflammation, hepatocellular ballooning, and fibrosis. A score system was utilized to evaluate each feature. An overall score, namely the NAFLD activity score (NAS), was generated based on the individual scores of all the histological features [33].

\subsection{Antioxidant Activity Tests}

The antioxidant assays of the three extracts of $P$. niruri were carried out in triplicate at a concentration of $10 \mathrm{mg} / \mathrm{mL}$. Absorbance was measured using a microplate reader (TECAN Infinite Pro ${ }^{\circledR}$ M200, Mannedorf, Switzerland). Total phenolic content (TPC) of each extract was estimated using Folin-Ciocalteu reagent, according to the method of Kumaran and Joel Karunakaran [34]. Gallic acid was used as the standard. TPC was expressed as $\mu \mathrm{g}$ gallic acid equivalent/mg dry extract. Total flavonoid content (TFC) of each extract was measured using the aluminium chloride method [35]. Quercetin was used as a reference standard. TFC was expressed as $\mu \mathrm{g}$ quercetin equivalent/mg dry extract. DPPH scavenging activity was assessed according to the method developed by Al-Mansoub et al. [36]. Ascorbic acid was used as the reference standard. The scavenging activity was expressed as $\mathrm{IC}_{50}$. ABTS scavenging activity was performed using the method described by Al-Mansoub et al. [36]. Ascorbic acid was used as reference standard. Results were expressed as $\mathrm{IC}_{50}$. The ferric reducing antioxidant power of each extract (FRAP) was carried out by the method of Benzie and Strain [37]. All results were expressed as nmol $\mathrm{Fe}^{+2}$ equivalent/mg dry extract.

\subsection{In Vitro Assay to Determine the Inhibitory Effects of the Most Active Extract on $\alpha$-Glucosidase, Pancreatic Lipase and Cholesterol Micellization}

The inhibitory activity of the most active extract against $\alpha$-glucosidase was measured based on previous method described by Yusoff et al. [38] with minor modification. The results were expressed as values of $\mathrm{IC}_{50}$ which is defined as the concentration of the sample/acarbose required to inhibit $50 \%$ of $\alpha$-glucosidase activity. Absorbance reading was taken using a microplate reader (TECAN Infinite Pro ${ }^{\circledR}$ M200, Mannedorf, Switzerland). All analyses were done in triplicate. Six serial dilutions of each sample were used to obtain the $\mathrm{IC}_{50}$ values. The inhibitory effect of the active extract towards pancreatic lipase was assessed by fluorometric assay based on the method described by Zhang et al. [39,40], using orlistat as the standard. The results were expressed as $\mathrm{IC}_{50}$ which is defined as the concentration of either sample or orlistat required to inhibit $50 \%$ of pancreatic lipase activity.

The inhibitory activity of most active extract of P. niruri against cholesterol micelle formation was carried out based on a previously reported method with minor modifications [41], using gallic acid as the positive control and a total cholesterol test kit for cholesterol determination. 


\subsection{Phytochemical Analysis by High-Performance Liquid Chromatography (HPLC)}

To standardize the most active extract and further elucidate its chemical composition and active compounds, an HPLC analysis was performed. Stock solutions $(1000 \mu \mathrm{g} / \mathrm{mL})$ of two selected marker compounds (ellagic acid and phyllanthin) were prepared in methanol. The chromatographic separation was carried out using a Zorbax Eclipse Plus C18 column and HPLC device (Agilent, Santa Clara, CA, USA). Column specifications were $250 \times 4.6 \mathrm{~mm} / 5 \mu \mathrm{m}$ particle size. The samples $(10 \mu \mathrm{L})$ were eluted at a flow rate of $1 \mathrm{~mL} / \mathrm{min}$ at a $\lambda_{\max }$ of $230 \mathrm{~nm}$, with a gradient mobile phase comprising $0.2 \%$ aqueous acetic acid and acetonitrile. The lowest limit of detection (LOD) value for each marker compounds was determined by analysing the standard concentrations successively with a 2-fold dilution with methanol. The concentration with the smallest detectable peak at a noise-to-signal ratio of 3 was considered as the LOD value. Moreover, the lower linearity range limit at 83 noise-to-signal ratio of 10 was deemed as the limit of quantification (LOQ) [42]. Each working standard solution was injected $(n=5)$ to determine the precision of the method. The values were expressed as the coefficient of variation $(\mathrm{CV} \%)$. Intra-day accuracy and precision analyses were carried out by injecting the working standard concentrations ( $n=5$ ) within one day, whereas the intra-day analyses were conducted by injecting the standard working concentrations once per day for five consecutive days (Murugaiyah and Chan, 2007). Three working standard concentrations of each selected marker compound were used to determine the percentage of recovery. The percentage of recovery was calculated for each analyte according to the equation below [43]:

$$
\text { Recovery }(\%)=\mathrm{A}-\mathrm{B} / \mathrm{C} \times 100
$$

where, $\mathrm{A}=$ amount of marker compound detected; $\mathrm{B}=$ original amount of the marker compound; $\mathrm{C}=$ amount of the marker compound spiked.

Ellagic acid and phyllanthin were quantified in P. niruri extract. The extract $(1 \mathrm{mg} / \mathrm{mL})$ was prepared in methanol for HPLC analysis. All the samples were filtered by $0.45 \mu \mathrm{m}$ PTFE syringe filter. The selected marker compounds were quantified in triplicates using linear regression equations of the calibration curves.

\subsection{Statistical Analysis}

The results were expressed as means \pm S.E.M. Statistical significant difference was examined using Statistical Package of Social Sciences (SPSS) program, version 20 (IBM Corp., Armonk, NY, USA). Differences between groups were evaluated using the one-way analysis of variance (ANOVA), followed by Dunnett's post hoc test, and was considered significant when $p<0.05$.

\section{Results}

\subsection{P. niruri Reduced Hepatomegaly and Visceral Adiposity}

The results revealed that the liver to body weight ratio in the HFD group was $51.4 \%$ higher than in the normal control (NC) group. Similarly, the visceral fat to body weight ratio was $48.6 \%$ higher in the HFD group compared to the NC group $(p<0.01)$, indicating that HFD rats developed hepatomegaly and visceral adiposity. These changes were reversed by metformin and 50\% ME of P. niruri, both of which significantly inhibited the increase in liver weight compared with the HFD group by $22.5 \%$ $(p<0.01)$ and $15.8 \%(p<0.05)$, respectively (Figure $1 \mathrm{~A})$, while the visceral fat weight was significantly reduced in groups treated with metformin, WE, $50 \% \mathrm{ME}$, and ME of $P$. niruri by $28.7 \%, 24.9 \%, 22.5 \%$, and $26.5 \%$, respectively, compared with the HFD group (Figure 1B). 

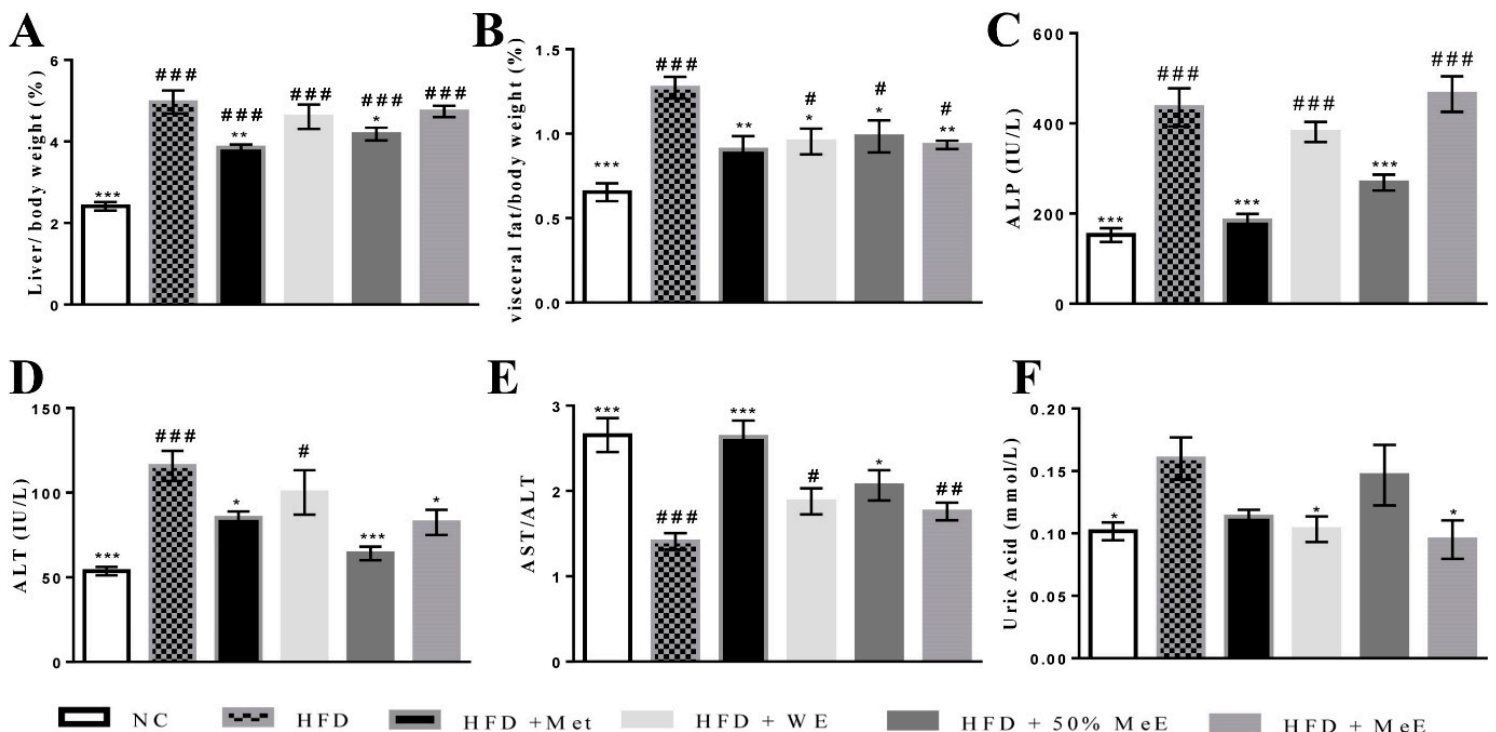

$\mathbf{E}$
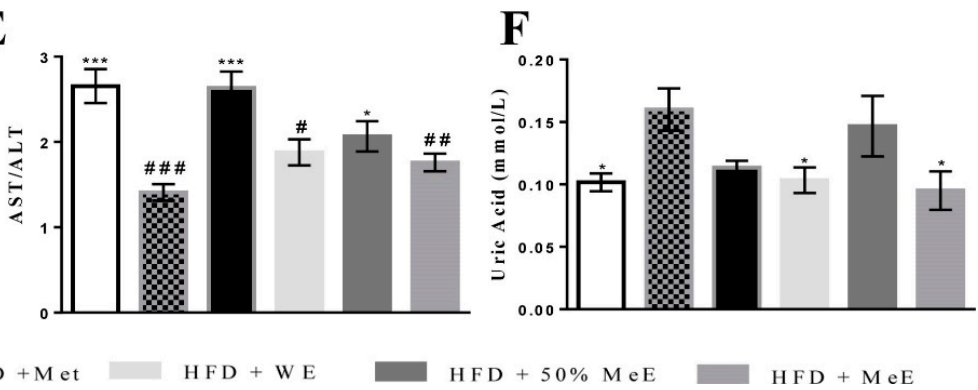

Figure 1. Effect of P. niruri extracts and metformin on liver weight and visceral fat ratios, serum liver enzymes and serum uric acid in high fat diet-fed rats. (A) Liver/body weight \%; (B) visceral fat/body weight \%; (C) ALP; Alkaline phosphatase; (D) ALT; Alanine aminotransferase; (E) AST/ALT; (F) serum uric acid. (Results expressed as mean $\pm \operatorname{SEM}(n=6){ }^{*} p<0.05,{ }^{* *} p<0.01,{ }^{* * *} p<0.001$ vs. HFD, and ${ }^{\#} p<0.05,{ }^{\# \#} p<0.01,{ }^{\# \#} p<0.001$ vs. NC group). NC; Normal control, HFD; High fat diet, Met; Metformin, WE; Water extract, MeE; Methanolic extract, SEM; Standard error mean.

\subsection{P. niruri Improved Abnormalities in Serum Indicators of NAFLD Rats}

To assess the development of NAFLD in the HFD model, the serum indicators correlated with NAFLD were measured. As shown in Figures 1 and 2 and Table 1, levels of glucose, total cholesterol, LDL, CRI-I, CRI-II, AC, and uric acid were significantly increased by $21.5 \%, 73.1 \%, 93.3 \%, 65.9 \%, 92.7 \%$, $90.2 \%$, and $36.5 \%$, respectively (all $p<0.01$ except uric acid $p<0.05$ ) in the HFD group when compared with the NC group. Moreover, liver enzymes including ALP and ALT levels were also rapidly doubled (both $p<0.01$ ), with no significant effect on AST, while AST / ALT ratio was decreased by almost half in the HFD group as compared to the normal diet group. However, the changes induced by HFD in TG, HDL, AST, total bilirubin, creatinine and urea levels were not statistically significant. On the other hand, compared with the HFD group, treatment with metformin, WE, 50\% ME, and ME of P. niruri has showed enhanced reduction in the levels of TC by $54.7 \%, 41.3 \%, 48.3 \%$, and $41.6 \%$, respectively. LDL was lowered by $74.65 \%, 57.13 \%, 64.68 \%$, and $43 \%$, respectively. CRI-II was reduced by $74.71 \%, 59.38 \%$, $65.89 \%$, and $41.43 \%$, respectively. AC values were also decreased by $73.3 \%, 58.9 \%, 64.4 \%$, and $36 \%$, respectively. However, only the treatment with metformin and 50\% ME of $P$. niruri exhibited significant additional effects including the reduction of glucose by $21.2 \%$ and $15.5 \%$, respectively; CRI-I by $46.7 \%$ and $29.3 \%$, respectively; ALP levels by $57.6 \%$ and $38.3 \%$, respectively; as well as improving AST / ALT ratios by $48 \%$ and $43.3 \%$, respectively. ALT was significantly decreased in rats treated with metformin by $26.5 \%$, ME of $P$. niruri by $28.8 \%$ (both $p<0.05$ ), and $50 \%$ ME $44.6 \%$ by $(p<0.01$ ), whereas uric acid was significantly restored to normal value after treatment with WE and ME of $P$. niruri $(p<0.05)$.

\subsection{P. niruri Decreased FFAs and Insulin Resistance}

To evaluate the extent of insulin resistance in our model, we further measured the serum concentration of FFAs and insulin. Our results showed that eight weeks of oral administration of HFD has increased serum FFAs by $29.8 \%(p<0.01)$, and serum insulin level by $68.8 \%(p<0.01)$ and HOMA-IR by $75.7 \%(p<0.01)$, indicating that rats the HFD developed distinct insulin resistance. However, treatment with metformin, WE, 50\% ME, and ME of $P$. niruri markedly reduced FFAs by 
$26.2 \%, 15.9 \%, 25.3 \%$, and $32.5 \%$, respectively, restored insulin levels to normal, and ameliorated insulin resistance (Figure 2).
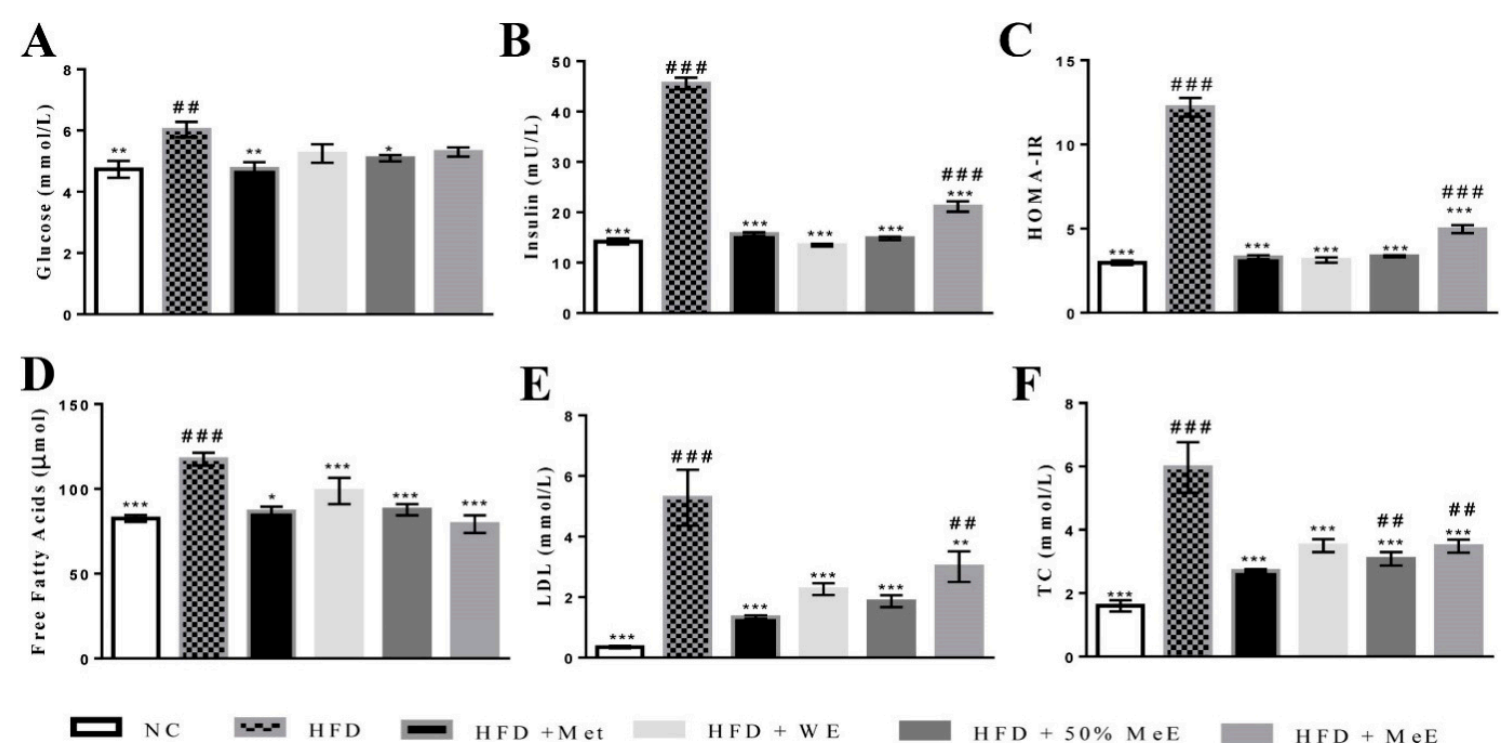

--- HFD

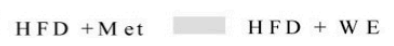

$\mathrm{HFD}+50 \% \mathrm{MeE}$

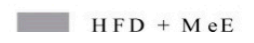

Figure 2. Effect of P. niruri extracts and metformin on serum levels of glucose, insulin, HOMA-IR, FFAs, LDL and TC in HFD-fed rats. (A) Serum levels of glucose; (B) serum levels of insulin; (C) serum levels of HOMA-IR; (D) serum levels of FFAs; (E) serum levels of LDL; (F) serum levels of TC. (Results expressed as mean $\pm \operatorname{SEM}(n=6) .{ }^{*} p<0.05,{ }^{* *} p<0.01$; ${ }^{* * *} p<0.001$ vs. HFD, and ${ }^{\#} p<0.05$; \#\# $p<0.01$; \#\#\# $p<0.001$ vs. NC group). HOMA-IR; homeostatic model assessment of insulin resistance, FFAs; Free fatty acids, LDL; Low density lipoprotein, TC; Total cholesterol.

Table 1. Effect of $P$. niruri extracts and metformin on coronary risk indexes.

\begin{tabular}{ccccccc}
\hline Parameters & NC Group & HFD Group & HFD + Met & HFD + WE & HFD + 50\% ME & HFD + ME \\
\hline CRI-I = TC/HDL & $1.53 \pm 0.03^{\mathrm{b}}$ & $4.50 \pm 0.57^{\mathrm{d}}$ & $2.40 \pm 0.10^{\mathrm{b}}$ & $3.53 \pm 0.26^{\mathrm{d}}$ & $3.18 \pm 0.16^{\mathrm{a}, \mathrm{d}}$ & $4.48 \pm 0.39^{\mathrm{d}}$ \\
CRI-II = LDL/HDL & $0.41 \pm 0.05^{\mathrm{b}}$ & $5.62 \pm 1.10^{\mathrm{d}}$ & $1.42 \pm 0.19^{\mathrm{b}}$ & $2.28 \pm 0.24^{\mathrm{b}}$ & $1.92 \pm 0.17^{\mathrm{b}}$ & $3.29 \pm 0.44^{\mathrm{a}, \mathrm{d}}$ \\
AC = (TC-HDL)/HDL & $0.60 \pm 0.06^{\mathrm{b}}$ & $6.14 \pm 1.18^{\mathrm{d}}$ & $1.64 \pm 0.21^{\mathrm{b}}$ & $2.52 \pm 0.26^{\mathrm{b}}$ & $2.18 \pm 0.16^{\mathrm{b}}$ & $3.93 \pm 0.64^{\mathrm{a}, \mathrm{d}}$ \\
\hline
\end{tabular}

Values are expressed as mean $\pm \mathrm{SEM}^{\mathrm{a}} p<0.05$ vs. HFD group; ${ }^{\mathrm{b}} p<0.01$ vs. HFD group; ${ }^{\mathrm{c}} p<0.05 \mathrm{vs}$. NC group and ${ }^{\mathrm{d}} p<0.01$ vs. NC group.

\subsection{P. niruri Reduced the Liver Content of TC, TG and Oxidative Stress Indicator}

Fat accumulation and lipid peroxidation in liver plays an essential role in the development of NAFLD [15]. To study the effects of $P$. niruri extracts on NAFLD progress in HFD-fed rats, we measured the content of hepatic TC, TG and MDA. High-fat diet caused a significant lipid droplet accumulation. Our results showed considerable increase in hepatic content of triglycerides by $28.9 \%$, total cholesterol by $50.5 \%$ and malondialdehyde (MDA) levels by $78.2 \%$ compared to the normal control group (all $p<0.01$ ). However, hepatic cholesterol levels were significantly reduced by $30.9 \%$, $44 \%, 43 \%$, and $40.2 \%$ after four weeks of oral administration of metformin, WE, 50\% ME, and ME of P. niruri, respectively (all $p<0.01$ ). Moreover, notable decreases in the hepatic triglycerides levels were observed in animals treated with $50 \%$ ME by $28.9 \%(p<0.01)$ and ME by $23.3 \%(p<0.05)$. On the other hand, the results revealed that the increase in hepatic malondialdehyde has been significantly inhibited in groups treated with WE by $70 \%(p<0.05), 50 \%$ ME by $40.1 \%(p<0.01)$ and ME by $38.8 \%$ $(p<0.01)$ compared with the HFD group (Figure 3). 


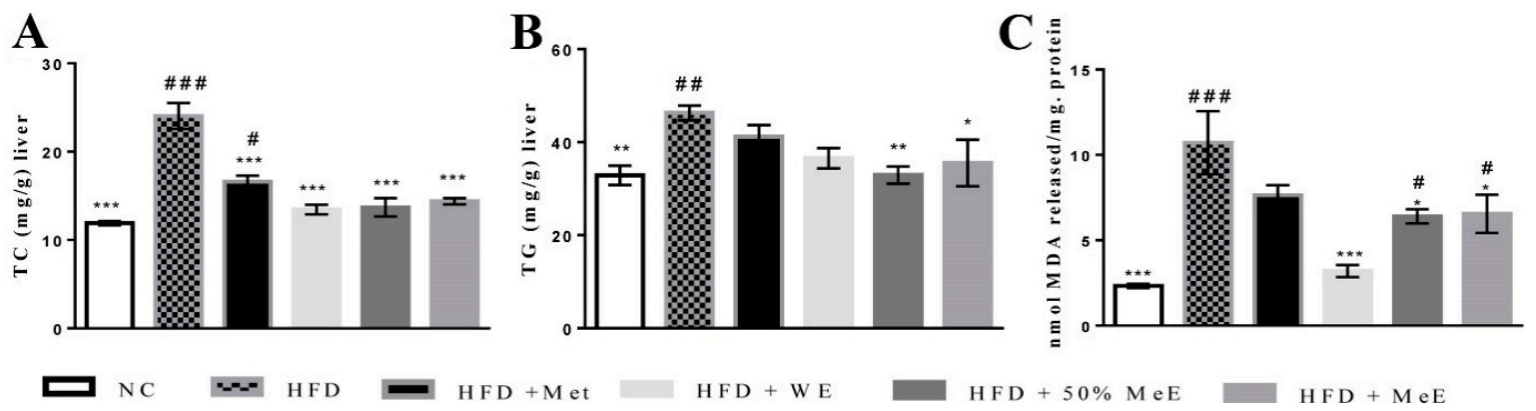

Figure 3. Effect of P. niruri extracts and metformin on Hepatic levels of TC, TG and MDA: (A) hepatic levels of TC; (B) hepatic levels of TG; (C) hepatic levels of MDA. (Results expressed as mean \pm SEM $(n=6) .{ }^{*} p<0.05,{ }^{* *} p<0.01,{ }^{* * *} p<0.001$ vs. HFD, and $\# p<0.05$, \#\# $p<0.01$, \#\#\# $p<0.001$ vs. NC group). TG; triglycerides, MDA; malondialdehyde.

\subsection{Effects of P. niruri on the Liver Histopathology}

Liver biopsy is considered to be the gold standard in NAFLD diagnosis [44]. Therefore, to confirm the onset of NAFLD in the animal model, histological analysis was performed as described in other studies $[45,46]$. Steatosis, hepatocyte ballooning and inflammation were assessed and scores (Table 2) were given individually. The individual scores were added together to produce the overall NAFLD activity score (NAS).

Table 2. Grading NAFLD activity score (NAS) [47].

\begin{tabular}{cccc}
\hline Steatosis & Ballooning & Lobular Inflammation & NAS \\
\hline$<5 \%(0)$ & None $(0)$ & None $(0)$ & 0 \\
$5-33 \%(1)$ & Rare or few $(1)$ & $1-2$ foci per $20 \times$ field $(1)$ & 3 \\
$34-66 \%(2)$ & Many (2) & $2-4$ foci $/ 20 \times$ field $(2)$ & 6 \\
$>66 \%(3)$ & Many $(2)$ & $>4$ foci $/ 20 \times$ field $(3)$ & 8 \\
\hline
\end{tabular}

Histological evaluation of liver samples from HFD group showed significant fat deposition with highest scores in steatosis, lobular multifocal portal inflammation, hepatocyte ballooning and fibrosis, significantly higher than those of the normal control group $(p<0.01)$. Hence, rats fed the high-fat diet developed definite NAFLD. Furthermore, the severe inflammation with fibrosis in the HFD-fed rats obviously confirmed the progression from NAFLD to NASH in the HFD group. However, the severity of the degenerative changes decreased following four weeks of metformin administration and all the P. niruri extracts, which resulted in significant suppression of steatosis, lobular inflammation, and NAS, but caused no considerable changes in hepatocyte ballooning (Figure 4 and Table 3).

Table 3. Analysis of NAS scores for all groups.

\begin{tabular}{ccccc}
\hline $\begin{array}{c}\text { Experimental } \\
\text { Groups }\end{array}$ & Steatosis & $\begin{array}{c}\text { Lobular } \\
\text { Inflammation }\end{array}$ & $\begin{array}{c}\text { Hepatocyte } \\
\text { Ballooning }\end{array}$ & NAS \\
\hline NC & $0^{\mathrm{b}}$ & $0^{\mathrm{b}}$ & $0^{\mathrm{b}}$ & $0^{\mathrm{b}}$ \\
HFD & $3 \pm 0^{\mathrm{d}}$ & $1.83 \pm 0.17^{\mathrm{d}}$ & $2 \pm 0$ & $6.83 \pm 0.17^{\mathrm{d}}$ \\
HFD + Met & $1.5 \pm 0.34^{\mathrm{b}, \mathrm{d}}$ & $0.67 \pm 0.21^{\mathrm{b}}$ & $1.83 \pm 0.16^{\mathrm{d}}$ & $4 \pm 0.63^{\mathrm{b}, \mathrm{d}}$ \\
HFD + WE & $2 \pm 0.26^{\mathrm{a}, \mathrm{d}}$ & $1.33 \pm 0.33^{\mathrm{d}}$ & $2 \pm 0^{\mathrm{d}}$ & $5.33 \pm 0.42^{\mathrm{a}, \mathrm{d}}$ \\
HFD + 50\% ME & $1.5 \pm 0.22^{\mathrm{b}, \mathrm{d}}$ & $1 \pm 0^{\mathrm{a}, \mathrm{c}}$ & $2 \pm 0^{\mathrm{d}}$ & $4.5 \pm 0.22^{\mathrm{b}, \mathrm{d}}$ \\
HFD + ME & $1.67 \pm 0.21^{\mathrm{b}, \mathrm{d}}$ & $1 \pm 0.26^{\mathrm{a}, \mathrm{c}}$ & $2 \pm 0^{\mathrm{d}}$ & $4.67^{\mathrm{d}} \pm 0.42^{\mathrm{b}, \mathrm{d}}$ \\
\hline
\end{tabular}

Values are expressed as mean $\pm \mathrm{SEM}^{\mathrm{a}} p<0.05$ vs. HFD group; ${ }^{\mathrm{b}} p<0.01$ vs. HFD group; ${ }^{\mathrm{c}} p<0.05$ vs. NC group and ${ }^{\mathrm{d}} p<0.01$ vs. NC group. 

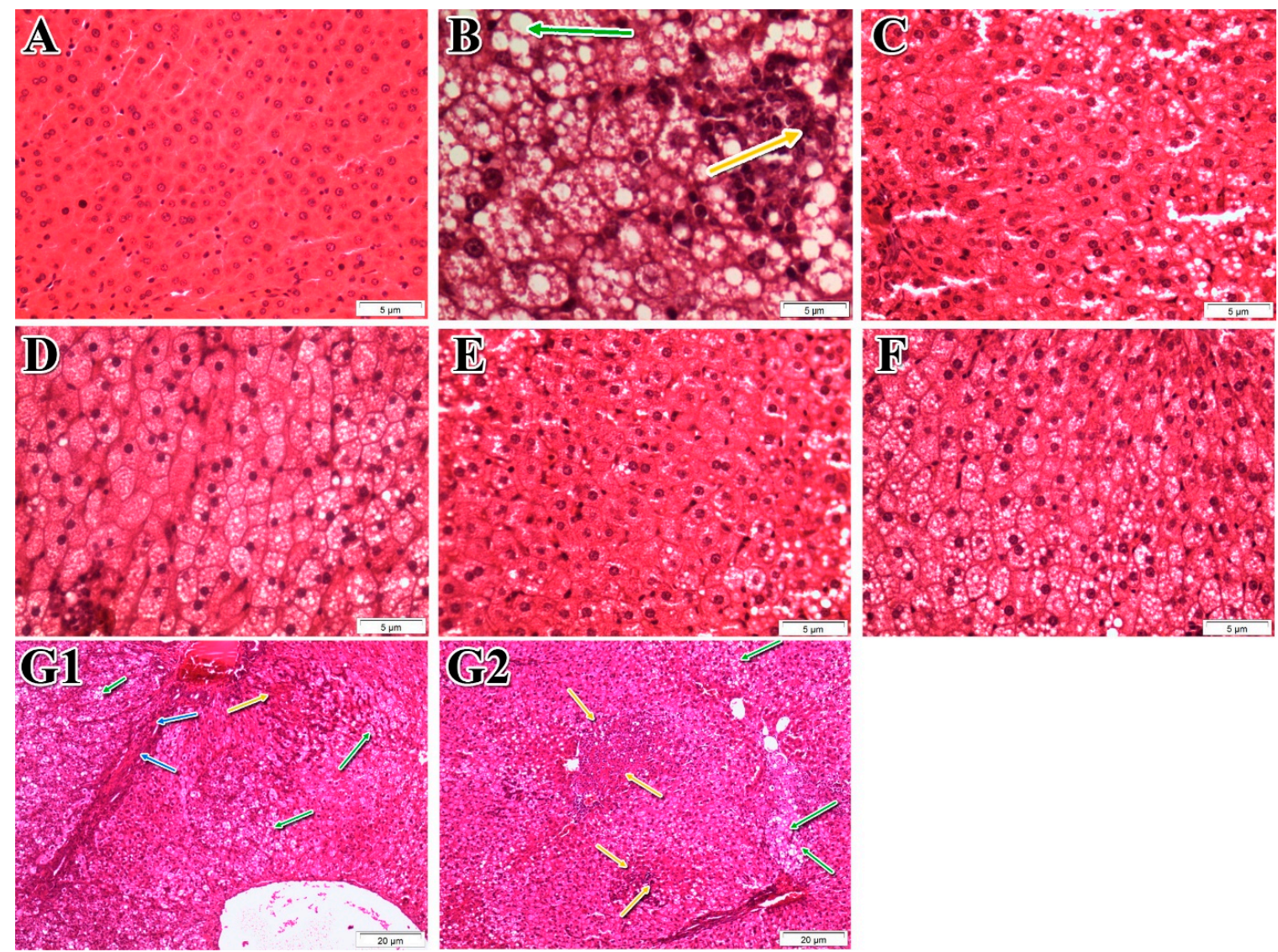

Figure 4. Effect of P. niruri extracts and metformin on the histological evaluation of liver biopsy. Typical liver tissue sections $(400 \times)$ stained with haematoxylin and eosin $(\mathrm{H} \& \mathrm{E})$. (A) NC group, showing normal tissue structure and architecture with no steatosis; (B) HFD group showed vesicular steatosis and inflammation (typical NAFLD); (C) HFD + metformin (500 mg/kg); (D) HFD + WE (1000 mg/kg); (E) HFD + 50\% ME (1000 mg/kg) and (F) HFD + ME (1000 mg/kg). The severe hepatic damage (inflammation and fibrosis) in HFD rats is further shown in the Figure 4G1,G2 (100×) stained with haematoxylin and eosin (H\&E), (G1) HFD group showed steatosis (green arrows) with fibrosis (blue arrows) $(100 \times)$; (G2) HFD group showed lobular inflammation (yellow arrows) $(100 \times)$.

\subsection{In Vitro Tests for the $50 \%$ ME of P. niruri}

Our biochemical and histological findings showed that $50 \%$ ME of $P$. niruri exhibited superior therapeutic effects among the treated groups. The 50\% ME of P. niruri $(2.5,5,10$ and $20 \mathrm{mg} / \mathrm{mL})$ exhibited inhibitory activity against the artificially prepared micelles of cholesterol in a dose-dependent manner by $4.27 \pm 0.50 \%, 5.79 \pm 2.10 \%, 12.03 \pm 1.38 \%$, and $12.91 \pm 1.17 \%$, respectively, while gallic acid $(0.2 \mathrm{mg} / \mathrm{mL})$, the standard compound, inhibited the cholesterol micelles' formation by $23.05 \pm 0.40 \%$. The $50 \%$ ME of $P$. niruri also inhibited pancreatic lipase with $\mathrm{IC}_{50}$ value of $0.78 \pm 0.05 \mathrm{mg} / \mathrm{mL}$. However, it had less potent activity than orlistat which was $0.20 \pm 0.01 \mu \mathrm{g} / \mathrm{mL}$. An $\alpha$-glucosidase inhibitory test demonstrated that $50 \%$ ME of P. niruri exhibited a strong inhibitory potential in a concentration-dependent manner. The percentage of inhibition ranged from $85.6 \%$ for the highest concentration $(0.156 \mathrm{mg} / \mathrm{mL})$ to $16.9 \%$ for the lowest concentration $(0.0049 \mathrm{mg} / \mathrm{mL})$. Moreover, the magnitude of inhibition of $\alpha$-glucosidase enzyme activities by $50 \%$ ME of $P$. niruri was comparable to the standard inhibitor, acarbose. With reference to the $\mathrm{IC}_{50}$ values, acarbose $\mathrm{IC}_{50}$ was $4.29 \pm 0.16 \mathrm{mg} / \mathrm{mL}$, whereas the $\mathrm{IC}_{50}$ of $50 \% \mathrm{ME}$ of $P$. niruri was $0.06 \pm 00.0 \mathrm{mg} / \mathrm{mL}$. The findings suggest that the inhibitory effects of $50 \%$ ME of $P$. niruri are more potent than acarbose. 


\subsection{The Effect of Different Doses of $50 \%$ ME of P. niruri on NAFLD}

As shown in Table 4, all doses of 50\% ME significantly decreased serum cholesterol, LDL, CRI-I, ALT, Insulin concentrations and HOMA-IR and increased the AST/ALT ratio. However, only the dose of $1000 \mathrm{mg} / \mathrm{kg}$ was able to significantly improve the histological parameters (Figure 5).

Table 4. The effect of different doses of $50 \%$ ME on NAFLD.

\begin{tabular}{|c|c|c|c|c|c|}
\hline Parameters & NC & HFD & \multicolumn{3}{|c|}{ HFD + 50\% ME } \\
\hline Liver/body weight (\%) & $2.69 \pm 0.21^{b}$ & $5.80 \pm 0.11^{\mathrm{d}}$ & $4.22 \pm 0.37^{\mathrm{a}}$ & $4.98 \pm 0.12$ & $4.79 \pm 0.11$ \\
\hline Glucose $(\mathrm{mmol} / \mathrm{L})$ & $4.60 \pm 0.27^{a}$ & $5.42 \pm 0.26^{c}$ & $4.54 \pm 0.11^{b}$ & $4.68 \pm 0.10^{\mathrm{a}}$ & $4.80 \pm 0.10$ \\
\hline $\mathrm{TC}(\mathrm{mmol} / \mathrm{L})$ & $1.64 \pm 0.09^{b}$ & $7.06 \pm 0.85^{\mathrm{d}}$ & $4.18 \pm 0.39^{b}$ & $4.64 \pm 0.54^{b, c}$ & $4.76 \pm 0.82^{b, c}$ \\
\hline CRI-I = TC/HDL & $1.66 \pm 0.05^{b}$ & $7.40 \pm 0.66^{\mathrm{d}}$ & $4.38 \pm 0.26^{b}$ & $5.26 \pm 0.54^{\mathrm{a}, \mathrm{d}}$ & $5.76 \pm 0.50 \mathrm{a}, \mathrm{d}$ \\
\hline CRI-II = LDL $/ \mathrm{HDL}$ & $0.42 \pm 0.03^{b}$ & $6.79 \pm 0.57^{\mathrm{d}}$ & $3.27 \pm 0.34^{\mathrm{a}}$ & $3.83 \pm 0.45$ & $4.54 \pm 0.49$ \\
\hline $\mathrm{AC}=(\mathrm{TC}-\mathrm{HDL}) / \mathrm{HDL}$ & $0.65 \pm 0.06^{b}$ & $6.99 \pm 0.58^{d}$ & $3.37 \pm 0.25^{\mathrm{a}}$ & $4.27 \pm 0.56$ & $6.47 \pm 0.73^{d}$ \\
\hline $\mathrm{ALP}(\mathrm{IU} / \mathrm{L})$ & $230.60 \pm 20.18^{a}$ & $558.20 \pm 34.75^{c}$ & $301.00 \pm 9.54^{\mathrm{a}}$ & $316.60 \pm 21.76^{a}$ & $431.00 \pm 35.05$ \\
\hline $\mathrm{ALT}(\mathrm{IU} / \mathrm{L})$ & $67.20 \pm 5.32^{b}$ & $107.80 \pm 12.68^{\mathrm{d}}$ & $65.60 \pm 5.90^{b}$ & $70.60 \pm 1.44^{\mathrm{b}}$ & $59.40 \pm 2.18^{b}$ \\
\hline Lobular inflammation & $0.00 \pm 0.00^{b}$ & $2.00 \pm 0.00^{\mathrm{d}}$ & $1.00 \pm 0.00^{\mathrm{a}}$ & $1.20 \pm 0.20$ & $1.20 \pm 0.20$ \\
\hline Hepatocyte ballooning & $0.00 \pm 0.00^{b}$ & $2.00 \pm 0.00$ & $2.00 \pm 0.00$ & $2.00 \pm 0.00$ & $2.00 \pm 0.00$ \\
\hline NAS & $0.00 \pm 0.00^{b}$ & $7.00 \pm 0.00^{d}$ & $4.20 \pm 0.20^{\mathrm{a}, \mathrm{c}}$ & $4.60 \pm 0.24^{d}$ & $5.20 \pm 0.37^{\mathrm{d}}$ \\
\hline
\end{tabular}

Results are expressed as mean \pm SEM, compared to HFD group. ${ }^{a} p<0.05$ vs. HFD group; ${ }^{b} p<0.01$ vs. HFD group; ${ }^{c} p<0.05$ vs. normal group; ${ }^{\mathrm{d}} p<0.01$ vs. normal group.
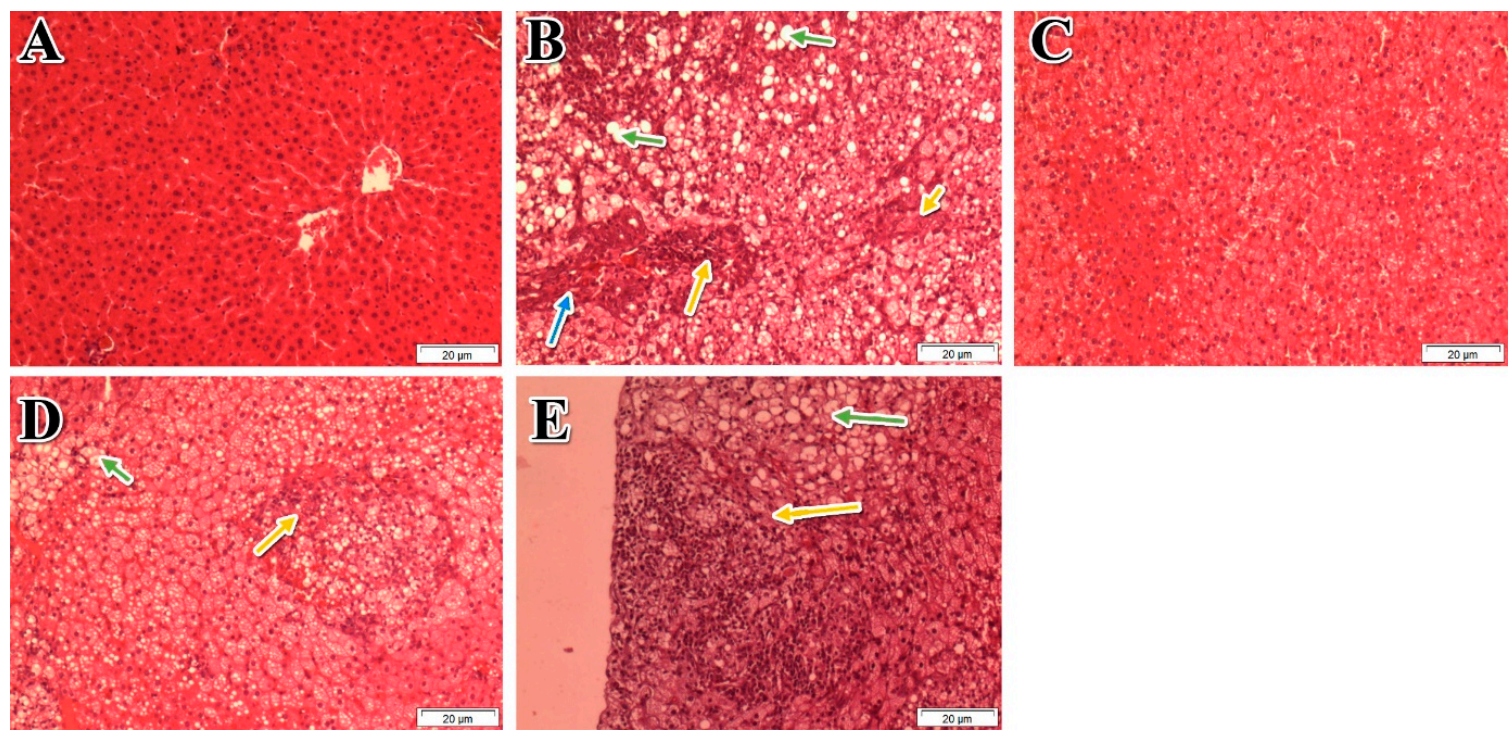

Figure 5. Microscopic examination of liver tissues stained with H\&E after four-week treatment with different doses of 50\% ME under 100× magnification. (A) Normal tissue structure; (B) steatosis, severe inflammation and fibrosis in HFD group; (C) marked reduction of NAFLD pathological manifestations at dose $1000 \mathrm{mg} / \mathrm{kg}$ of $50 \% \mathrm{ME}$; (D) moderate steatosis and inflammation at dose $500 \mathrm{mg} / \mathrm{kg}$ of ME50; (E) severe inflammation at the dose $250 \mathrm{mg} / \mathrm{kg}$ of ME 50 (green arrows: steatosis; yellow arrows: inflammation, blue arrows: fibrosis). 


\subsection{Total Phenolic Content (TPC), Total Flavonoid Content (TFC) and Anti-Oxidative Activities of P. niruri}

The highest total phenolic and flavonoid contents were found in 50\% ME of P. niruri with the highest antioxidant activities in DPPH and ABTS tests (Table 5).

Table 5. Anti-oxidative activities and phytochemical screening of P. niruri extracts.

\begin{tabular}{|c|c|c|c|c|c|}
\hline & $\begin{array}{l}\text { Total Phenolic } \\
\text { ( } \mu \text { g Gallic Acid } \\
\text { Equiv./mg } \\
\text { Extract) }\end{array}$ & $\begin{array}{l}\text { Total Flavonoid } \\
\text { ( } \mu \mathrm{g} \text { Quercetin } \\
\text { Equiv./mg } \\
\text { Extract) }\end{array}$ & $\begin{array}{l}\text { DPPH IC } \\
(\mu \mathrm{g} / \mathrm{mL})\end{array}$ & $\begin{array}{l}\text { ABTS IC } 50 \\
(\mu \mathrm{g} / \mathrm{mL})\end{array}$ & $\begin{array}{l}\text { FRAP (nmol } \\
\mathrm{Fe}^{+2} \text { Equiv./mg } \\
\text { Extract) }\end{array}$ \\
\hline WE & $224.13 \pm 1.14$ & $39.41 \pm 0.72$ & $7.38 \pm 0.84$ & $31.94 \pm 1.36$ & $272.56 \pm 4.39$ \\
\hline $50 \%$ ME & $323.98 \pm 0.33$ & $64.46 \pm 1.36$ & $2.72 \pm 0.25$ & $26.51 \pm 0.63$ & $220.01 \pm 1.90$ \\
\hline ME & $237.87 \pm 0.46$ & $49.85 \pm 0.62$ & $8.32 \pm 0.29$ & $99.66 \pm 0.98$ & $333.95 \pm 11.73$ \\
\hline $\begin{array}{l}\text { Ascorbic acid } \\
\text { (Standard) }\end{array}$ & - & - & $1.51 \pm 0.22$ & $5.73 \pm 0.09$ & - \\
\hline
\end{tabular}

Values are expressed as mean \pm SEM $(n=3)$. DPPH; 2,2-diphenyl-1-picrylhydrazyl, ABTS; 2,2-azinobis

(3-ethyl-benzothiazoline-6-sulfonic acid) and FRAP; ferric reducing antioxidant power.

\subsection{Extract Standardization by HPLC Analysis}

All selected marker compounds showed good linear regression with high correlation coefficient values $\left(R^{2} \geq 0.999\right)$ between the peak area and the concentration. LOD was 0.20 and $0.52 \mu \mathrm{g} / \mathrm{mL}$, respectively; and LOQ values were 0.78 and $1.56 \mu \mathrm{g} / \mathrm{mL}$, respectively, for ellagic acid and phyllanthin. Figure 6 shows a representative HPLC chromatogram of mixed standard compounds. Peaks appeared at $6.33 \mathrm{~min}$ for ellagic acid and at $15.95 \mathrm{~min}$ for phyllanthin. The recovery percentages for the selected marker compounds in P. niruri extract are presented in Table 6. Recovery values for the concentrations used ranged from $99.25 \%$ to $104.75 \%$ and from $100.04 \%$ to $102.65 \%$ for ellagic acid and phyllanthin, respectively. The recovery data were deemed satisfactory, leading to the conclusion that our extraction methodology did not cause substantial loss of those compounds. Data pertaining to the intra- and inter-day accuracy and precision obtained after analysing the selected marker compounds are summarised in Table 6. The accuracy values, expressed as percentages of the true values, were $95.90 \%$ and $104.94 \%$ for ellagic acid and phyllanthin, respectively. The corresponding precision values, expressed as $\mathrm{CV} \%$, totalled $0.18 \%$ and $4.78 \%$ for intra-day and inter-day analyses, respectively. This indicated that the method used was reliable and reproducible. Ellagic acid and phyllanthin were quantified in $P$. niruri using the HPLC technique described earlier. The HPLC chromatogram of P. niruri extract is shown in Figure 7. The HPLC-UV method used here was developed for simultaneous determination of ellagic acid and phyllanthin. Analysis revealed that that $P$. niruri contained several peaks at different retention times, demonstrating that multiple components were detected. However, the retention times of ellagic acid and phyllanthin were approximately 6.32-15.92 min. Both ellagic acid and phyllanthin were major compounds in P. niruri extract, with phyllanthin making up over $10 \%$ and ellagic acid comprising nearly $2 \%$ of the extract. We believe that the HPLC method used in this work can be used as a standard analytical method for the quantification of marker compounds in P. niruri extract. 


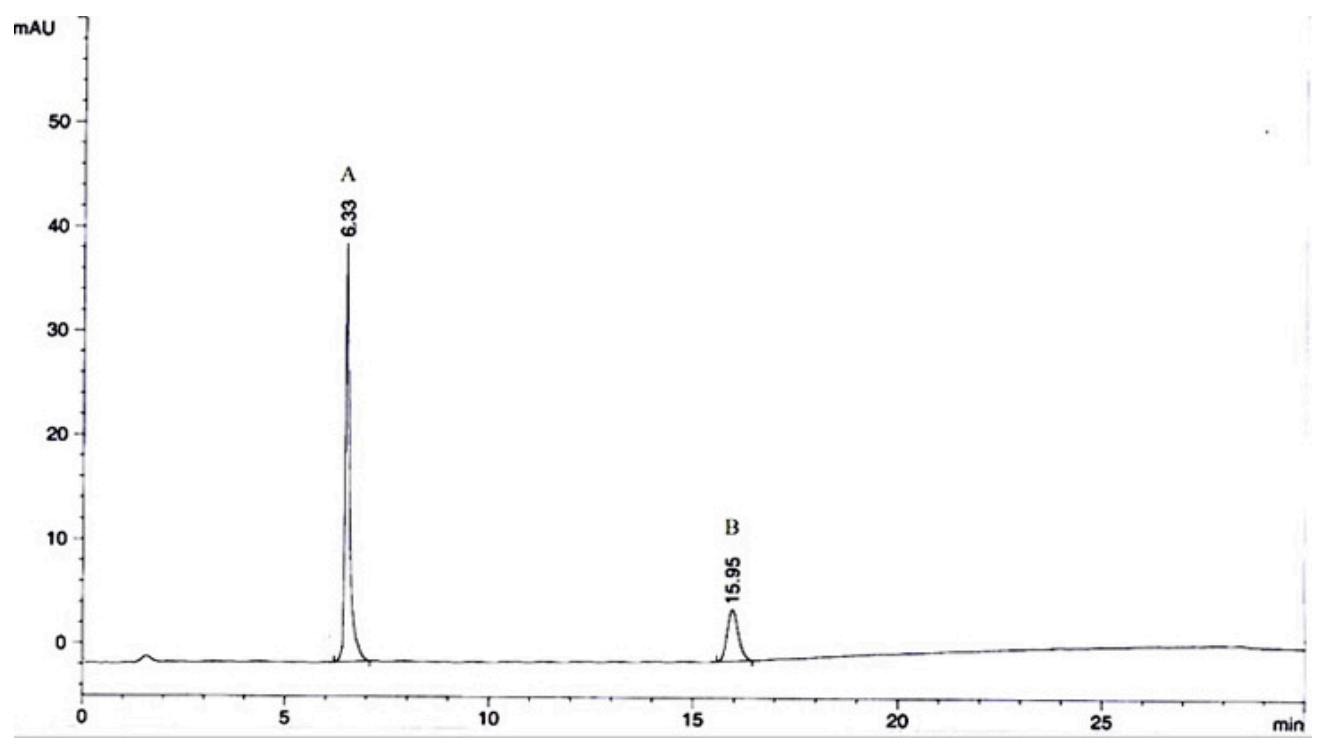

Figure 6. High performance liquid chromatography chromatogram of mixed standard compounds. A: ellagic acid; B: phyllanthin.

Table 6. Percentage recovery, within-day and between-day precision and accuracy values for ellagic acid and phyllanthin in P. niruri extract.

\begin{tabular}{|c|c|c|c|c|c|c|c|}
\hline \multirow{2}{*}{ Compounds } & \multirow{2}{*}{$\begin{array}{c}\text { Concentrations } \\
(\mu \mathrm{g} / \mathrm{mL})\end{array}$} & \multicolumn{2}{|c|}{ Within-Day } & \multicolumn{2}{|c|}{ Between-Day } & \multicolumn{2}{|c|}{ Recovery } \\
\hline & & $\begin{array}{c}\text { Accuracy } \\
(\%)\end{array}$ & $\begin{array}{l}\text { Precision } \\
(\mathrm{CV} \%)\end{array}$ & $\begin{array}{c}\text { Accuracy } \\
(\%)\end{array}$ & $\begin{array}{l}\text { Precision } \\
\text { (CV\%) }\end{array}$ & Mean (\%) & $\begin{array}{l}\text { Mean } \\
(\mathrm{CV} \%)\end{array}$ \\
\hline \multirow{5}{*}{ Ellagic acid } & 50.00 & 100.30 & 0.18 & 100.01 & 0.27 & 99.25 & 0.80 \\
\hline & 6.25 & 97.50 & 0.19 & 97.66 & 2.64 & - & - \\
\hline & 3.12 & 102.18 & 0.26 & 100.50 & 2.09 & 104.75 & 2.18 \\
\hline & 1.56 & 104.36 & 0.51 & 100.64 & 2.83 & - & - \\
\hline & 0.78 & 104.62 & 0.67 & 104.89 & 4.15 & 103.62 & 3.90 \\
\hline \multirow{5}{*}{ Phyllanthin } & 25.00 & 96.28 & 0.25 & 98.47 & 1.82 & 102.65 & 1.19 \\
\hline & 12.50 & 104.94 & 1.28 & 102.50 & 3.27 & - & - \\
\hline & 6.25 & 104.42 & 4.78 & 100.42 & 1.45 & 100.04 & 1.49 \\
\hline & 3.12 & 100.83 & 0.28 & 101.10 & 2.63 & - & - \\
\hline & 1.56 & 95.90 & 2.04 & 98.35 & 4.77 & 101.31 & 3.41 \\
\hline
\end{tabular}

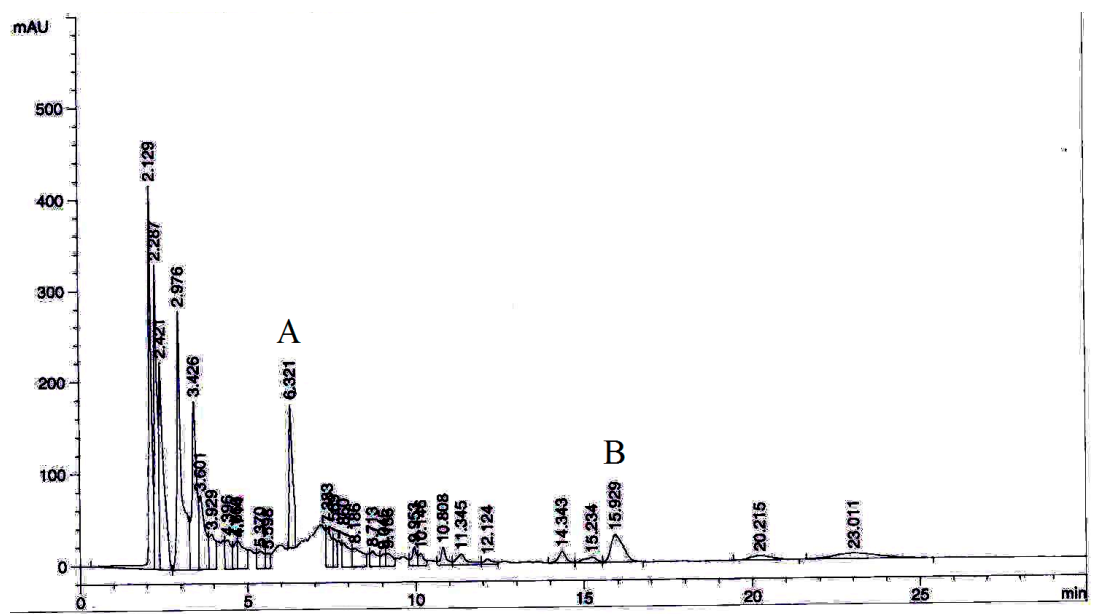

Figure 7. High performance liquid chromatography chromatogram of P. niruri extract. A: ellagic acid; B: phyllanthin. 


\section{Discussion}

Sedentary lifestyle and overconsumption of high-calorie foods are the main reasons for central obesity and NAFLD [48]. The present study provides strong evidence of the anti-NAFLD activity of $P$. niruri in SD rats. Our optimized extract of $P$. niruri not only supressed hepatic fat accumulation but also blocked inflammation in NAFLD rats, thus preventing fibrosis and inhibiting simple steatosis from progressing to NASH. Additionally, rats treated with $P$. niruri exhibited significantly lower indicators of atherosclerosis than untreated rats.

Our current in vivo model of NAFLD was successfully established and developed to NASH after feeding the rats with a HFD enriched with trans-fatty acids from margarine, and saturated fatty acids derived from animal fat $[49,50]$. The high increase in the weight of the liver and visceral fat in the HFD group is a prominent feature of NAFLD [51,52]. Furthermore, the hypercholesterolemia within HFD group was previously reported in 20-80\% of human NAFLD cases [53], and a greater concentration of serum FFAs is correlated with disease severity [54]. Moreover, the significant increase in serum levels of ALP and ALT in addition to the elevated hepatic content of TG, TC and MDA in NAFLD rats is a strong indicator of liver damage and oxidative stress [55]. According to the "two hit" hypothesis of NAFLD, high levels of free fatty acids lead to lipogenesis and lipid accumulation in the liver during the first hit of NAFLD progress, whereas the presence of oxidative stress and lipid peroxidation represents the second hit [56]. More specifically, the accumulated fats in the liver induce the release of cytotoxic oxygen free radicals, which are associated with lipid peroxidation markers such as malondialdehyde (MDA) [57] that trigger inflammation and fibrosis [58,59]. In the current study, HFD group exhibited higher concentrations of glucose and hyperinsulinemia, elevated HOMA-IR values, and developed significant hepatic steatosis, inflammation and fibrosis. These results are in agreement with previous studies and further prove the ability of a HFD to cause rapid fat accumulation in the liver, with distinct elevation in insulin resistance (HOMA-IR values) [60]. The increase of insulin resistance in the HFD group would stimulate oxidative stress in the liver by releasing reactive oxygen species, causing hepatic lipid peroxidation and initiating inflammatory reactions that enhance fibrosis through the activation of hepatic stellate cell (HSC) [3,61].

In addition, the significant increase in serum uric acid (SUA) concentration in the HFD group led to the development of NAFLD and insulin resistance. It was reported that hyperuricemia is closely correlated with the severity of liver damage. Moreover, SUA can enhance inflammatory reactions and trigger oxidative stress in adipocytes, which in turn increases insulin resistance and induces more lipolysis in adipose tissue and greater oxidative stress in the liver cells [62]. Consequently, the reduction in SUA could improve NAFLD [63]. Similarly, the present findings suggest that decreasing the SUA level in WE- and ME-treated groups contributed to the suppression of NAFLD in these groups.

The considerable increase in serum atherogenic indexes indicates a higher risk of atherosclerosis in NAFLD rats. This is attributed to the sharp increase in serum levels of LDL, which is usually oxidized to form the peroxides that play a role in several atherosclerotic stages by their cytotoxic effects, leading to endothelial injury [64].

However, 50\% ME of P. niruri was the most active among the three extracts of the plant. It prominently decreased visceral adipose tissue and liver weight, and blocked the progress of NAFLD by the reduction in hepatic steatosis and inflammation. In addition to preventing fibrosis, it improved liver function and decreased serum levels of glucose, insulin concentrations and HOMA-IR, indicating a significant decrease in insulin resistance. It was obvious from the results that $P$. niruri improved cross-talk between the liver and adipose tissues. This was reflected by the lower serum concentrations of TC, LDL and FFAs in NAFLD rats [65]. The 50\% ME of $P$. niruri also supressed FFA-evoked de novo lipogenesis in the liver and decreased the hepatic content of cholesterol, TG, and MDA. As a result, the atherogenic ratios were evidently decreased. The results show that all doses (1000 mg/kg, $500 \mathrm{mg} / \mathrm{kg}$, and $250 \mathrm{mg} / \mathrm{kg})$ of $50 \% \mathrm{ME}$ are able to significantly reduce atherogenic ratios, ALT, AST/ALT ratio, and suppress insulin resistance. On the other hand, liver weight, visceral adipose tissue weight and liver histology were only improved by the dose of $1000 \mathrm{mg} / \mathrm{kg}$, indicating that this is the anti-NAFLD effective dose. 
The anti-NAFLD effect of $P$. niruri is likely to result from the antioxidant activity shown by DPPH and ABTS tests. This is most likely attributable to phenolic compounds in all P. niruri extracts that inhibited oxidative stress by decreasing lipid peroxidation and improving insulin signalling and $\beta$-oxidation. These results are in agreement with many previous studies that explained the potent antioxidant activities of polyphenols in suppressing lipogenesis and inhibiting fatty acid synthesis in vitro [14]. The anti-NAFLD effect of $50 \%$ ME of $P$. niruri may also be due to ellagic acid, an active antioxidant that was a major compound in the extract. It was previously found to be responsible for anti-NAFLD effect of Phyllanthus emblica L. in vitro [66]. Ellagic acid was further reported to decrease de novo lipogenesis, inhibit TG esterification and enhance FFAs oxidation by increasing the expression of FFAs oxidative genes in the liver, leading to significant reduction of hepatic lipid accumulation [67]. It was suggested that this activity is due to the increase in energy expenditure by enhancing AMPK, the regulator of energy homeostasis and FFAs oxidation [68]. It is anticipated that $50 \% \mathrm{ME}$ of P. niruri might act by a similar mechanism.

Another anti-oxidant agent and bioactive compound in 50\% ME of P. niruri is phyllanthin, which has been reported to be effective in ameliorating the development of NAFLD in mice [69]. The other possible mechanism that might contribute to the anti-NAFLD effect of $50 \mathrm{ME}$ of $P$. niruri is inhibiting the activities of $\alpha$-glucosidase, pancreatic lipase and cholesterol micellization. Since high rates of carbohydrate and fat consumption increase insulin resistance and oxidative stress [70], improving insulin signalling can be achieved by decreasing the intake of carbohydrates and lipids, and attenuating the postprandial hyperlipidemia. This might contribute by decreasing the hepatic cholesterol and FFAs pool required for the de novo lipogenesis process in the liver [71-73]. The same mechanism was also suggested for acarbose, orlistat and ezetimibe as a prospective treatment for lipid metabolic disorders such as obesity and other insulin resistance complications including NAFLD and diabetes $[59,74,75]$.

The oral consumption of $P$. niruri is considered safe, and investigations into its toxicity in female Sprague-Dawley rats have not shown any abnormality in different body organs. The LD50 was higher than $5000 \mathrm{mg} / \mathrm{kg}$ body weight [76]. Moreover, it is noteworthy that $P$. niruri was clinically approved to be safely consumed by children [77].

In summary, 50\% ME of $P$. niruri reduced visceral adiposity, improved liver enzymes abnormalities, and decreased hepatic lipid peroxidation and fat accumulation. It also decreased the risk of atherosclerosis related to NAFLD, induced by a high-fat diet in SD rats. The data suggest that the antioxidant and hypolipidemic effects of the bioactive components in $50 \% \mathrm{ME}$ of $P$. niruri (ellagic acid and phyllanthin) play essential roles in the therapeutic properties. Hence, the current study established the first-ever report on the potential therapeutic use of P. niruri as a natural source for treating NAFLD. The general mechanism of anti-NAFLD effect of action of P. niruri is shown in Scheme 1.

High dietary fat consumption combines with an increased rate of lipolysis in the insulin-resistant adipose tissues, leading to elevated free fatty acid (FFAs) concentrations in the blood. The excessive free fatty acids are delivered to the insulin-resistant liver, which has impaired mitochondrial $\beta$-oxidation. Excessive intake of carbohydrates, along with insulin resistance, result in channelling high quantities of glucose to the liver, where it is converted to either glycogen or FFAs via insulin-stimulated de novo lipogenesis (DNL), leading to excessive accumulation of triglycerides and cholesterol in the liver. P. niruri decreased insulin resistance, reduced serum fatty acids, and inhibited $\alpha$-glucosidase, pancreatic lipase and cholesterol micellization, leading to a decrease in the amounts of glucose and FFAs in the liver. Consequently, fewer FFAs and less glucose will be available to the de novo lipogenesis process, and therefore less fat will accumulate in the liver. P. niruri also reduced hepatic MDA, the marker of lipid peroxidation, which stimulates hepatic stellate cells (HSC), the main cells that are responsible for triggering fibrosis in the liver. As a result, P. niruri reduced hepatic fibrosis.

The yellow arrows denote the weakened pathway in NAFLD, while the black arrows refer to the stimulated pathway in NAFLD. The blue symbol indicates the inhibitory effect of $P$. niruri. 


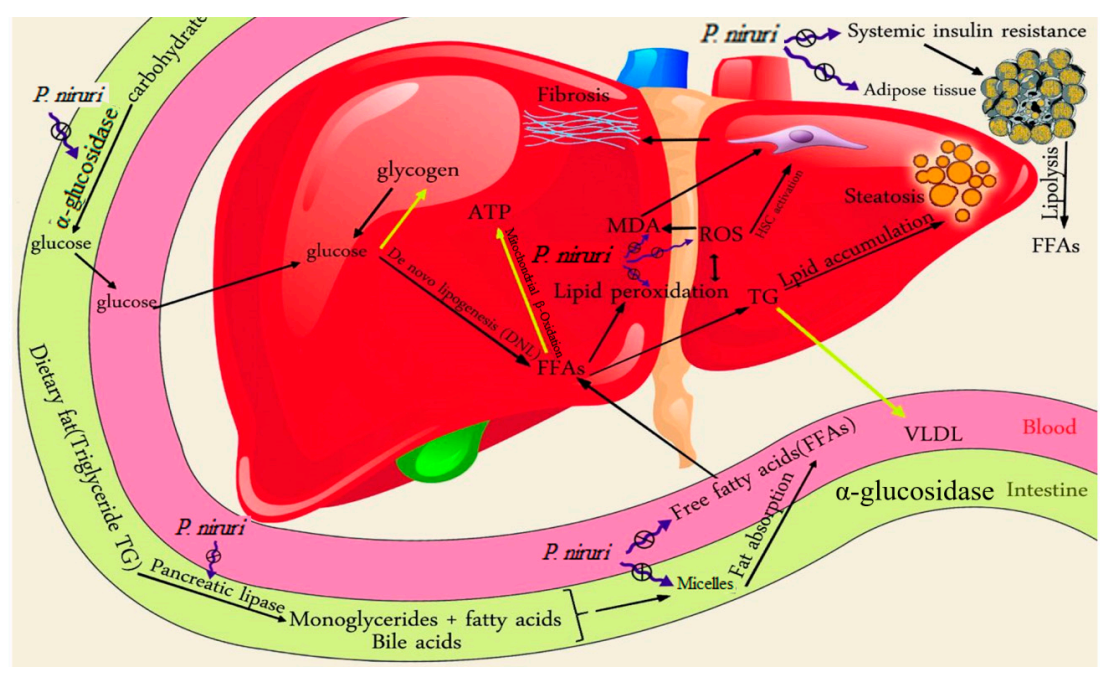

Scheme 1. A schematic diagram simplifying the sites of action of P. niruri on some of the pathogenic features of NAFLD.

Acknowledgments: The researchers would like to thank the School of Pharmaceutical Sciences, University Sains Malaysia, for providing the necessary facility and financial support for this research. Special thanks go to Safia Akhtar Khan, Adlin Yousof, Bassel Al Hindi, Abdul Menem Bakory and Idiri Bello (USM Malaysia), Sawsan AL Madi, Ayman Ali (Damascus University), Issam Sabbagh and Wafiqa Zarzour from School of Pharmacy at Arab International University (AIU) for their great assistance. This work was in part supported by the fundamental research grant scheme (FRGS), ministry of education, Malaysia, No.: 203/PFARMASI/6711451.

Author Contributions: Raghdaa Hamdan Al Zarzour; established, designed and performed the whole study, Mariam Ahmad, Mun Fei Yam and Mohd. Zaini Asmawi; helped in designing the study and establishing the animal model and flow chart of the study, Nasiba Salisu Usman, Majed Ahmed Al-Mansoub, Sultan Ayesh Mohammed Saghir; helped in performing the in vivo and in vitro assays, Gurjeet Kaur; performed the histopathological examination and NAFLD scoring, Mohammed Ali Ahmed Saeed; helped in the development, validation and standardization of the extract compounds using HPLC. Dhamraa W. Al-Dulaimi; helped in performing the statistical analysis.

Conflicts of Interest: The authors declared that they have no conflict of interest.

\section{References}

1. Abenavoli, L.; Milic, N.; di Renzo, L.; Preveden, T.; Medić-Stojanoska, M.; de Lorenzo, A. Metabolic aspects of adult patients with nonalcoholic fatty liver disease. World J. Gastroenterol. 2016, 22, 7006. [CrossRef] [PubMed]

2. Tzanetakou, I.P.; Doulamis, I.P.; Korou, L.-M.; Agrogiannis, G.; Vlachos, I.S.; Pantopoulou, A.; Mikhailidis, D.P.; Patsouris, E.; Vlachos, I.; Perrea, D.N. Water Soluble Vitamin E Administration in Wistar Rats with Non-alcoholic Fatty Liver Disease. Open Cardiovasc. Med. J. 2012, 6, 88. [CrossRef] [PubMed]

3. Videla, L.A.; Rodrigo, R.; Araya, J.; Poniachik, J. Insulin resistance and oxidative stress interdependency in non-alcoholic fatty liver disease. Trends Mol. Med. 2006, 12, 555-558. [CrossRef] [PubMed]

4. Comar, K.; Sterling, R. Review article: Drug therapy for non-alcoholic fatty liver disease. Aliment. Pharmacol. Ther. 2006, 23, 207-215. [CrossRef] [PubMed]

5. Vernon, G.; Baranova, A.; Younossi, Z. Systematic review: The epidemiology and natural history of non-alcoholic fatty liver disease and non-alcoholic steatohepatitis in adults. Aliment. Pharmacol. Ther. 2011, 34, 274-285. [CrossRef] [PubMed]

6. Milic, S.; Stimac, D. Nonalcoholic fatty liver disease/steatohepatitis: Epidemiology, pathogenesis, clinical presentation and treatment. Dig. Dis. 2012, 30, 158-162. [CrossRef] [PubMed]

7. Charlton, M.; Kasparova, P.; Weston, S.; Lindor, K.D.; Maor-Kendler, Y.; Wiesner, R.H.; Rosen, C.B.; Batts, K.P. Frequency of nonalcoholic steatohepatitis as a cause of advanced liver disease. Liver Transplant. 2001, 7, 608-614. [CrossRef] [PubMed] 
8. Staprans, I.; Pan, X.M.; Rapp, J.H.; Feingold, K.R. The role of dietary oxidized cholesterol and oxidized fatty acids in the development of atherosclerosis. Mol. Nutr. Food Res. 2005, 49, 1075-1082. [CrossRef] [PubMed]

9. Angulo, P. Nonalcoholic fatty liver disease. N. Engl. J. Med. 2002, 346, 1221-1231. [CrossRef] [PubMed]

10. Calzadilla Bertot, L.; Adams, L.A. The natural course of non-alcoholic fatty liver disease. Int. J. Mol. Sci. 2016, 17, 774. [CrossRef] [PubMed]

11. Boursier, J.; Mueller, O.; Barret, M.; Machado, M.; Fizanne, L.; Araujo-Perez, F.; Guy, C.D.; Seed, P.C.; Rawls, J.F.; David, L.A. The severity of nonalcoholic fatty liver disease is associated with gut dysbiosis and shift in the metabolic function of the gut microbiota. Hepatology 2016, 63, 764-775. [CrossRef] [PubMed]

12. Hamad, E.M.; Taha, S.H.; Abou Dawood, A.; Sitohy, M.Z.; Abdel-Hamid, M. Protective effect of whey proteins against nonalcoholic fatty liver in rats. Lipids Health Dis. 2011, 10, 57. [CrossRef] [PubMed]

13. Hanhineva, K.; Törrönen, R.; Bondia-Pons, I.; Pekkinen, J.; Kolehmainen, M.; Mykkänen, H.; Poutanen, K. Impact of dietary polyphenols on carbohydrate metabolism. Int. J. Mol. Sci. 2010, 11, 1365-1402. [CrossRef] [PubMed]

14. Kim, H.J.; Kim, H.J.; Lee, K.E.; Kim, D.J.; Kim, S.K.; Ahn, C.W.; Lim, S.; Kim, K.R.; Lee, H.C.; Huh, K.B. Metabolic significance of nonalcoholic fatty liver disease in nonobese, nondiabetic adults. Arch. Int. Med. 2004, 164, 2169-2175. [CrossRef] [PubMed]

15. Gaggini, M.; Morelli, M.; Buzzigoli, E.; de Fronzo, R.A.; Bugianesi, E.; Gastaldelli, A. Non-alcoholic fatty liver disease (NAFLD) and its connection with insulin resistance, dyslipidemia, atherosclerosis and coronary heart disease. Nutrients 2013, 5, 1544-1560. [CrossRef] [PubMed]

16. Kashi, M.R.; Torres, D.M.; Harrison, S.A. Current and Emerging Therapies in Nonalcoholic Fatty Liver Disease; Seminars in liver disease; Thieme Medical Publishers, Inc.: New York, NY, USA, 2008; pp. 396-406.

17. Filippatos, T.D.; Elisaf, M.S. Role of ezetimibe in non-alcoholic fatty liver disease. World J. Hepatol. 2011, 3 , 265-267. [CrossRef] [PubMed]

18. Nozaki, Y.; Fujita, K.; Yoneda, M.; Wada, K.; Shinohara, Y.; Takahashi, H.; Kirikoshi, H.; Inamori, M.; Kubota, K.; Saito, S. Long-term combination therapy of ezetimibe and acarbose for non-alcoholic fatty liver disease. J. Hepatol. 2009, 51, 548-556. [CrossRef] [PubMed]

19. Paithankar, V.; Raut, K.; Charde, R.; Vyas, J. Phyllanthus niruri: A magic herb. Res. Pharm. 2015, 1, 1-9.

20. Milosevic, N.; Milanovic, M.; Abenavoli, L.; Milic, N. Phytotherapy and NAFLD-from goals and challenges to clinical practice. Rev. Recent Clin. Trials 2014, 9, 195-203. [CrossRef] [PubMed]

21. Pradeep, K.; Mohan, C.V.R.; Gobianand, K.; Karthikeyan, S. Silymarin modulates the oxidant-antioxidant imbalance during diethylnitrosamine induced oxidative stress in rats. Eur. J. Pharmacol. 2007, 560, 110-116. [CrossRef] [PubMed]

22. Dong, H.; Lu, F.-E.; Gao, Z.-Q.; Xu, L.-J.; Wang, K.-F.; Zou, X. Effects of emodin on treating murine nonalcoholic fatty liver induced by high caloric laboratory chaw. World J. Gastroenterol. 2005, 11, 1339-1344. [CrossRef] [PubMed]

23. Bagalkotkar, G.; Sagineedu, S.R.; Saad, M.S.; Stanslas, J. Phytochemicals from Phyllanthus niruri Linn. and their pharmacological properties: A review. J. Pharm. Pharmacol. 2006, 58, 1559-1570. [CrossRef] [PubMed]

24. Freitas, A.; Schor, N.; Boim, M.A. The effect of Phyllanthus niruri on urinary inhibitors of calcium oxalate crystallization and other factors associated with renal stone formation. BJU Int. 2002, 89, 829-834. [CrossRef] [PubMed]

25. Shanmugam, B.; Shanmugam, K.R.; Ravi, S.; Subbaiah, G.V.; Ramakrishana, C.; Mallikarjuna, K.; Reddy, K.S. Exploratory studies of (-)-Epicatechin, a bioactive compound of Phyllanthus niruri, on the antioxidant enzymes and oxidative stress markers in D-galactosamine-induced hepatitis in rats: A study with reference to clinical prospective. Pharmacogn. Mag. 2017, 13, S56. [CrossRef] [PubMed]

26. Rani, S.; Kumar, B. Efficacy of Phyllanthus niruri Linn. Extract in the management of type-2 diabetes mellitus associated hypercholesterolemia in mice diabetic model. Int. J. Curr. Microbiol. Appl. Sci. 2015, 4, 507-513.

27. Shajib, M.S.; Akter, S.; Ahmed, T.; Imam, M.Z. Antinociceptive and neuropharmacological activities of methanol extract of Phoenix sylvestris fruit pulp. Front. Pharm. 2015, 6, 212. [CrossRef] [PubMed]

28. Pramyothin, P.; Ngamtin, C.; Poungshompoo, S.; Chaichantipyuth, C. Hepatoprotective activity of Phyllanthus amarus Schum. et. Thonn. extract in ethanol treated rats: In vitro and in vivo studies. J. Ethnopharmacol. 2007, 114, 169-173. [CrossRef] [PubMed] 
29. Manjrekar, A.; Jisha, V.; Bag, P.; Adhikary, B.; Pai, M.; Hegde, A.; Nandini, M. Effect of Phyllanthus niruri Linn. treatment on liver, kidney and tests in $\mathrm{CCl}_{4}$ induced hepatotoxic rats. Indian J. Exp. Biol. 2008, 46, 514. [PubMed]

30. Bhardwaj, S.; Bhattacharjee, J.; Bhatnagar, M.; Tyagi, S. Atherogenic index of plasma, castelli risk index and atherogenic coefficient-new parameters in assessing cardiovascular risk. Int. J. Pharm. Bio Sci. 2013, 3, 359-364.

31. Ohkawa, H.; Ohishi, N.; Yagi, K. Assay for lipid peroxides in animal tissues by thiobarbituric acid reaction. Anal. Biochem. 1979, 95, 351-358. [CrossRef]

32. Folch, J.; Lees, M.; Sloane-Stanley, G. A simple method for the isolation and purification of total lipids from animal tissues. J. Biol. Chem. 1957, 226, 497-509. [PubMed]

33. Gurau, G.; Coman, M.; Dinu, C.A.; Busila, C.; Voicu, D.C.; Macovei, L.A.; Calin, A.M. The Electrophoretic Patterns of Serum Proteins in Children. Rev. Chim. 2016, 67, 190-194.

34. Kumaran, A.; Joel Karunakaran, R. In vitro antioxidant activities of methanol extracts of five Phyllanthus species from India. LWT-Food Sci. Technol. 2007, 40, 344-352. [CrossRef]

35. Orhan, N.; Orhan, I.E.; Ergun, F. Insights into cholinesterase inhibitory and antioxidant activities of five Juniperus species. Food Chem. Toxicol. 2011, 49, 2305-2312. [CrossRef] [PubMed]

36. Al-Mansoub, M.A.; Asmawi, M.; Murugaiyah, V. Effect of extraction solvents and plant parts used on the antihyperlipidemic and antioxidant effects of Garcinia atroviridis: A comparative study. J. Sci. Food Agric. 2014, 94, 1552-1558. [CrossRef] [PubMed]

37. Benzie, I.F.; Strain, J. The ferric reducing ability of plasma (FRAP) as a measure of "antioxidant power": The FRAP assay. Anal. Biochem. 1996, 239, 70-76. [CrossRef] [PubMed]

38. Yusoff, N.A.; Ahmad, M.; al Hindi, B.; Widyawati, T.; Yam, M.F.; Mahmud, R.; Razak, K.N.A.; Asmawi, M.Z. Aqueous Extract of Nypa fruticans Wurmb. Vinegar Alleviates Postprandial Hyperglycemia in Normoglycemic Rats. Nutrients 2015, 7, 7012-7026. [CrossRef] [PubMed]

39. Zhang, J.; Kang, M.; Kim, M.; Kim, M.; Song, J.; Lee, Y.; Kim, J. Pancreatic lipase inhibitory activity of taraxacum officinale in vitro and in vivo. Nutr. Res. Pract. 2008, 2, 200-203. [CrossRef] [PubMed]

40. Sugiyama, H.; Akazome, Y.; Shoji, T.; Yamaguchi, A.; Yasue, M.; Kanda, T.; Ohtake, Y. Oligomeric procyanidins in apple polyphenol are main active components for inhibition of pancreatic lipase and triglyceride absorption. J. Agric. Food Chem. 2007, 55, 4604-4609. [CrossRef] [PubMed]

41. Kirana, C.; Rogers, P.F.; Bennett, L.E.; Abeywardena, M.Y.; Patten, G.S. Naturally derived micelles for rapid in vitro screening of potential cholesterol-lowering bioactives. J. Agric. Food Chem. 2005, 53, 4623-4627. [CrossRef] [PubMed]

42. Murugaiyah, V.; Chan, K.-L. Determination of four lignans in Phyllanthus niruri L. by a simple high-performance liquid chromatography method with fluorescence detection. J. Chromatogr. A 2007, 1154, 198-204. [CrossRef] [PubMed]

43. Khalid, H.; Zhari, I.; Amirin, S.; Pazilah, I. Accelerated stability and chemical kinetics of ethanol extracts of fruit of piper sarmentosum using high performance liquid chromatography. Iran. J. Pharm. Res. 2011, 10, 403-413. [PubMed]

44. Chalasani, N.; Younossi, Z.; Lavine, J.E.; Diehl, A.M.; Brunt, E.M.; Cusi, K.; Charlton, M.; Sanyal, A.J. The diagnosis and management of non-alcoholic fatty liver disease: practice guideline by the American Gastroenterological Association, American Association for the Study of Liver Diseases, and American College of Gastroenterology. Gastroenterology 2012, 142, 1592-1609. [PubMed]

45. Brunt, E.M. Nonalcoholic Steatohepatitis: Definition and Pathology; Seminars in liver disease; Thieme Medical Publishers: New York, NY, USA, 2001; pp. 003-016. [CrossRef]

46. Kirsch, R.; Clarkson, V.; Shephard, E.G.; Marais, D.A.; Jaffer, M.A.; Woodburne, V.E.; Kirsch, R.E.; Hall, P.D.L.M. Rodent nutritional model of non-alcoholic steatohepatitis: Species, strain and sex difference studies. J. Gastroenterol. Hepatol. 2003, 18, 1272-1282. [CrossRef] [PubMed]

47. Kleiner, D.E.; Brunt, E.M.; van Natta, M.; Behling, C.; Contos, M.J.; Cummings, O.W.; Ferrell, L.D.; Liu, Y.; Torbenson, M.S.; Unalp-Arida, A. Design and validation of a histological scoring system for nonalcoholic fatty liver disease. Hepatology 2005, 41, 1313-1321. [CrossRef] [PubMed]

48. Loomba, R.; Sanyal, A.J. The global NAFLD epidemic. Nat. Rev. Gastroenterol. Hepatol. 2013, 10, 686-690. [CrossRef] [PubMed] 
49. Dhibi, M.; Brahmi, F.; Mnari, A.; Houas, Z.; Chargui, I.; Bchir, L.; Gazzah, N.; Alsaif, M.A.; Hammami, M. The intake of high fat diet with different trans fatty acid levels differentially induces oxidative stress and non alcoholic fatty liver disease (NAFLD) in rats. Nutr. Metab. 2011, 8, 1. [CrossRef] [PubMed]

50. Wei, Y.; Wang, D.; Topczewski, F.; Pagliassotti, M.J. Saturated fatty acids induce endoplasmic reticulum stress and apoptosis independently of ceramide in liver cells. Am. J. Phys.-Endocrinol. Metab. 2006, 291, E275-E281. [CrossRef] [PubMed]

51. Wu, J.; Zhang, H.; Zheng, H.; Jiang, Y. Hepatic inflammation scores correlate with common carotid intima-media thickness in rats with NAFLD induced by a high-fat diet. BMC Vet. Res. 2014, 10, 1. [CrossRef] [PubMed]

52. Chan, D.C.; Watts, G.F.; Ng, T.W.K.; Hua, J.; Song, S.; Barrett, P.H.R. Measurement of liver fat by magnetic resonance imaging: Relationships with body fat distribution, insulin sensitivity and plasma lipids in healthy men. Diabetes Obes. Metab. 2006, 8, 698-702. [CrossRef] [PubMed]

53. Souza, M.R.D.A.; Diniz, M.D.F.F.D.; Medeiros-Filho, J.M.D.; Araújo, M.S.T.D. Metabolic syndrome and risk factors for non-alcoholic fatty liver disease. Arq. Gastroenterol. 2012, 49, 89-96. [CrossRef] [PubMed]

54. Nehra, V.; Angulo, P.; Buchman, A.L.; Lindor, K.D. Nutritional and metabolic considerations in the etiology of nonalcoholic steatohepatitis. Dig. Dis. Sci. 2001, 46, 2347-2352. [CrossRef] [PubMed]

55. Xu, P.; Zhang, X.-G.; Li, Y.-M.; Yu, C.-H.; Xu, L.; Xu, G.-Y. Research on the protection effect of pioglitazone for non-alcoholic fatty liver disease (NAFLD) in rats. J. Zhejiang Univ. Sci. B 2006, 7, 627-633. [CrossRef] [PubMed]

56. Letteron, P.; Fromenty, B.; Benoît, T.; Degott, C.; Pessayre, D. Acute and chronic hepatic steatosis lead to in vivo lipid peroxidation in mice. J. Hepatol. 1996, 24, 200-208. [CrossRef]

57. Yokozawa, T.; Cho, E.J.; Sasaki, S.; Satoh, A.; Okamoto, T.; Sei, Y. The protective role of Chinese prescription Kangen-karyu extract on diet-induced hypercholesterolemia in rats. Biol. Pharm. Bull. 2006, 29, 760-765. [CrossRef] [PubMed]

58. Hsiao, P.-J.; Hsieh, T.-J.; Kuo, K.-K.; Hung, W.-W.; Tsai, K.-B.; Yang, C.-H.; Yu, M.-L.; Shin, S.-J. Pioglitazone retrieves hepatic antioxidant DNA repair in a mice model of high fat diet. BMC Mol. Biol. 2008, 9, 82. [CrossRef] [PubMed]

59. Mai, T.T.; Thu, N.N.; Tien, P.G.; CHUYEN, N.V. Alpha-glucosidase inhibitory and antioxidant activities of Vietnamese edible plants and their relationships with polyphenol contents. J. Nutr. Sci. Vitaminol. 2007, 53, 267-276. [CrossRef] [PubMed]

60. De Bari, O.; Neuschwander-Tetri, B.A.; Liu, M.; Portincasa, P.; Wang, D.Q.-H. Ezetimibe: Its novel effects on the prevention and the treatment of cholesterol gallstones and nonalcoholic Fatty liver disease. J. Lipids 2011, 2012, 302847. [CrossRef] [PubMed]

61. Day, C.P. Non-alcoholic fatty liver disease: Current concepts and management strategies. Clin. Med. 2006, 6, 19-25. [CrossRef]

62. Lanaspa, M.A.; Sanchez-Lozada, L.G.; Choi, Y.; Cicerchi, C.; Kanbay, M.; Roncal-Jimenez, C.A.; Ishimoto, T.; Li, N.; Marek, G.; Duranay, M. Uric Acid induces hepatic steatosis by generation of mitochondrial oxidative stress potential role in fructose-dependent and-independent fatty liver. J. Biol. Chem. 2012, 287, 40732-40744. [CrossRef] [PubMed]

63. Athyros, V.G.; Mikhailidis, D.P.; Liberopoulos, E.N.; Kakafika, A.I.; Karagiannis, A.; Papageorgiou, A.A.; Tziomalos, K.; Ganotakis, E.S.; Elisaf, M. Effect of statin treatment on renal function and serum uric acid levels and their relation to vascular events in patients with coronary heart disease and metabolic syndrome A subgroup analysis of the GREek Atorvastatin and Coronary heart disease Evaluation (GREACE) Study. Nephrol. Dial. Transplant. 2007, 22, 118-127. [PubMed]

64. Binder, C.J.; Hartvigsen, K.; Chang, M.-K.; Miller, M.; Broide, D.; Palinski, W.; Curtiss, L.K.; Corr, M.; Witztum, J.L. IL-5 links adaptive and natural immunity specific for epitopes of oxidized LDL and protects from atherosclerosis. J. Clin. Investig. 2004, 114, 427-437. [CrossRef] [PubMed]

65. Malhi, H.; Bronk, S.F.; Werneburg, N.W.; Gores, G.J. Free fatty acids induce JNK-dependent hepatocyte lipoapoptosis. J. Biol. Chem. 2006, 281, 12093-12101. [CrossRef] [PubMed]

66. Lu, C.-C.; Yang, S.-H.; Hsia, S.-M.; Wu, C.-H.; Yen, G.-C. Inhibitory effects of Phyllanthus emblica L. on hepatic steatosis and liver fibrosis in vitro. J. Funct. Foods 2016, 20, 20-30. [CrossRef] 
67. Okla, M.; Kang, I.; Kim, D.M.; Gourineni, V.; Shay, N.; Gu, L.; Chung, S. Ellagic acid modulates lipid accumulation in primary human adipocytes and human hepatoma Huh7 cells via discrete mechanisms. J. Nutr. Biochem. 2015, 26, 82-90. [CrossRef] [PubMed]

68. Kang, I. Mechanisms by Which Dietary Ellagic Acid Attenuates Obesity and Obesity-Mediated Metabolic Complications. Ph.D. Thesis, University of Nebraska, Lincoln, NE, USA, November 2015.

69. Jagtap, S.; Khare, P.; Mangal, P.; Kondepudi, K.K.; Bishnoi, M.; Bhutani, K.K. Protective effects of phyllanthin, a lignan from Phyllanthus amarus, against progression of high fat diet induced metabolic disturbances in mice. RSC Adv. 2016, 6, 58343-58353. [CrossRef]

70. Asrih, M.; Jornayvaz, F.R. Diets and nonalcoholic fatty liver disease: The good and the bad. Clin. Nutr. 2014, 33, 186-190. [CrossRef] [PubMed]

71. Van Rooyen, D.M.; Gan, L.T.; Yeh, M.M.; Haigh, W.G.; Larter, C.Z.; Ioannou, G.; Teoh, N.C.; Farrell, G.C. Pharmacological cholesterol lowering reverses fibrotic NASH in obese, diabetic mice with metabolic syndrome. J. Hepatol. 2013, 59, 144-152. [CrossRef] [PubMed]

72. Gonzalez, C.; de Ledinghen, V.; Vergniol, J.; Foucher, J.; Le Bail, B.; Carlier, S.; Maury, E.; Gin, H.; Rigalleau, V. Hepatic steatosis, carbohydrate intake, and food quotient in patients with NAFLD. Int. J. Endocrinol. 2013, 2013, 428542. [CrossRef] [PubMed]

73. Wang, X.; Ren, Q.; Wu, T.; Guo, Y.; Liang, Y.; Liu, S. Ezetimibe prevents the development of non-alcoholic fatty liver disease induced by high-fat diet in C57BL/6J mice. Mol. Med. Rep. 2014, 10, 2917-2923. [CrossRef] [PubMed]

74. Adisakwattana, S.; Charoenlertkul, P.; Yibchok-anun, S. $\alpha$-Glucosidase inhibitory activity of cyanidin-3-galactoside and synergistic effect with acarbose. J. Enzym. Inhib. Med. Chem. 2009, 24, 65-69. [CrossRef] [PubMed]

75. Lee, Y.A.; Cho, E.J.; Tanaka, T.; Yokozawa, T. Inhibitory activities of proanthocyanidins from persimmon against oxidative stress and digestive enzymes related to diabetes. J. Nutr. Sci. Vitaminol. 2007, 53, 287-292. [CrossRef] [PubMed]

76. Asare, G.; Addo, P.; Bugyei, K.; Gyan, B.; Adjei, S.; Otu-Nyarko, L.; Wiredu, E.; Nyarko, A. Acute toxicity studies of aqueous leaf extract of Phyllanthus Niruri. Interdiscip. Toxicol. 2011, 4, 206-210. [CrossRef] [PubMed]

77. Sarisetyaningtyas, P.V.; Hadinegoro, S.R.; Munasir, Z. Randomized controlled trial of Phyllanthus niruri Linn extract. Paediatr. Indones. 2016, 46, 77-81. [CrossRef] 